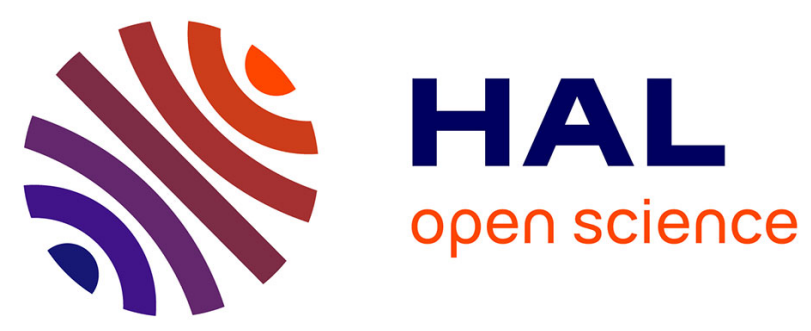

\title{
Development of a methodology for predicting particle attrition in a cyclone by CFD-DEM
}

Fabio Fulchini, Mojtaba Ghadiri, Antonia Borissova, Benjamin Amblard, Stéphane Bertholin, Ann Cloupet, Mahdi Yazdanpanah

\section{To cite this version:}

Fabio Fulchini, Mojtaba Ghadiri, Antonia Borissova, Benjamin Amblard, Stéphane Bertholin, et al.. Development of a methodology for predicting particle attrition in a cyclone by CFD-DEM. Powder Technology, 2019, 357, pp.21-32. 10.1016/j.powtec.2019.08.101 . hal-02445565

\section{HAL Id: hal-02445565 \\ https://hal-ifp.archives-ouvertes.fr/hal-02445565}

Submitted on 20 Jan 2020

HAL is a multi-disciplinary open access archive for the deposit and dissemination of scientific research documents, whether they are published or not. The documents may come from teaching and research institutions in France or abroad, or from public or private research centers.
L'archive ouverte pluridisciplinaire HAL, est destinée au dépôt et à la diffusion de documents scientifiques de niveau recherche, publiés ou non, émanant des établissements d'enseignement et de recherche français ou étrangers, des laboratoires publics ou privés. 


\title{
DEVELOPMENT OF A METHODOLOGY FOR PREDICTING PARTICLE ATTRITION IN A CYCLONE BY CFD-DEM
}

\author{
Fabio Fulchini ${ }^{a, b}$, Antonia Borissova ${ }^{a}$, Benjamin Amblard $^{b}$, Stephane Bertholin ${ }^{b}$, Ann \\ Cloupet $^{b}$, Mahdi Yazdanpanah ${ }^{c}$, Mojtaba Ghadiri $^{a^{*}}$ \\ ${ }^{\text {a }}$ School of Chemical and Process Engineering, University of Leeds, Leeds, UK; \\ ${ }^{\mathrm{b}}$ IFP Energies Nouvelles, Solaize, France \\ ${ }^{\mathrm{c}}$ TOTAL Research \& Technology Gonfreville, Le Havre, France \\ *Corresponding Author: m.ghadiri@leeds.ac.uk
}

\begin{abstract}
Cyclones are commonly used in the process industry to separate entrained particles from gas streams. Particles entering a cyclone are subjected to a centrifugal force field, driving them to the cyclone walls, where they experience collisional and rapid shearing stresses. Consequently, particle attrition and erosion of the cyclone walls occur, depending on the mechanical properties of the particles and cyclone walls.
\end{abstract}

In this work, the attrition of manganese oxide particles, intended for use in the Chemical Looping Combustion (CLC) process, flowing through a standard design cyclone (Stairmand design) is analysed as an example by considering surface damage processes of chipping and wear. A new methodology is developed, whereby Computational Fluid Dynamics-Discrete Element Method (CFD-DEM) simulations are used to analyse the particle motion and interactions with the cyclone walls. The approach is then coupled with breakage models of chipping and wear to predict the extent of attrition.

The impact breakage due to chipping is evaluated experimentally first as a function of particle size and impact angle and velocity. The data are fitted to the chipping model of Ghadiri and Zhang. The model is then coupled with the frequency of collisions and impact velocity, obtained from the CFD-DEM simulation, to work out the particle attrition by chipping. For surface wear the model of Archard is used to account for 
particle wear by shearing against the walls. The outcome of the work provides a methodology for describing the extent of attrition in different regions of the cyclone.

Keywords: Cyclone, attrition, CFD-DEM, impact damage, wear, CLC

\section{NOMENCLATURE}

\begin{tabular}{|c|c|c|}
\hline Symbol & Description & Unit measure \\
\hline \multicolumn{3}{|c|}{ Latin letters } \\
\hline $\mathrm{ACC}$ & Accumulation of particles in the cyclone & - \\
\hline $\mathrm{b}$ & intercept with the abscissa & - \\
\hline $\mathrm{d}_{0}$ & initial particle size & $\mu \mathrm{m}$ \\
\hline $\mathrm{d}_{\mathrm{m}}$ & mother particle size & $\mu \mathrm{m}$ \\
\hline $\mathrm{d}_{\mathrm{m}, \min }$ & mother particle size at $R_{\max }$ & $\mu \mathrm{m}$ \\
\hline$d_{p}$ & particle size & $\mu \mathrm{m}$ \\
\hline $\mathrm{d}_{\mathrm{s}}$ & sieve mesh size & $\mu \mathrm{m}$ \\
\hline $\mathrm{F}_{\mathrm{n}}$ & $\begin{array}{l}\text { normal compressive force acting on a particle during } \\
\text { sliding }\end{array}$ & $\mathrm{mN}$ \\
\hline $\mathrm{H}$ & particle hardness & $\mathrm{Pa}$ \\
\hline IN & Inlet particles flow rate in the cyclone & $\mathrm{s}^{-1}$ \\
\hline $\mathrm{K}_{\mathrm{c}}$ & particle fracture toughness & $\mathrm{Pa} \mathrm{m}^{-0.5}$ \\
\hline $\mathrm{m}_{0}$ & initial particle mass & $\mathrm{kg}$ \\
\hline $\mathrm{m}_{\mathrm{m}}$ & mother particle mass & $\mathrm{kg}$ \\
\hline$m_{\text {de }}$ & debris particle mass & $\mathrm{kg}$ \\
\hline $\mathrm{m}_{\text {loss }}$ & material loss & $\mathrm{kg}$ \\
\hline $\mathrm{m}_{\mathrm{de}, \max }$ & debris particle mass at $R_{\max }$ & $\mathrm{kg}$ \\
\hline $\mathrm{m}_{\mathrm{m}, \min }$ & mother particle mass at $\mathrm{R}_{\max }$ & $\mathrm{kg}$ \\
\hline$\dot{\mathrm{N}}_{\mathrm{c}}$ & frequency of collisions & $\mathrm{s}^{-1}$ \\
\hline $\mathrm{N}_{\mathrm{c} / \mathrm{p}}$ & number of collisions per particle & - \\
\hline $\mathrm{N}_{\mathrm{p}}$ & number of particles & - \\
\hline$\dot{\mathrm{N}}_{\mathrm{p}}$ & net flow of number of particles & $\mathrm{s}^{-1}$ \\
\hline$\dot{\mathrm{N}}_{\mathrm{p} 0}$ & net flow of number of particles at the inlet of the cyclone & $\mathrm{s}^{-1}$ \\
\hline $\mathrm{n}$ & number of regions of interest in the cyclone & - \\
\hline
\end{tabular}




\begin{tabular}{|c|c|c|}
\hline OUT & Outlet particles flow rate from the cyclone & $\mathrm{s}^{-1}$ \\
\hline $\mathrm{R}^{-}$ & $\begin{array}{l}\text { extent of breakage when losses are attributed to mother } \\
\text { particles }\end{array}$ & - \\
\hline $\mathrm{R}^{+}$ & $\begin{array}{l}\text { extent of breakage when losses are attributed to debris } \\
\text { particles }\end{array}$ & - \\
\hline $\mathrm{R}^{*}$ & extent of breakage when losses are ignored & - \\
\hline $\mathrm{R}$ & $\begin{array}{l}\text { extent of breakage when losses are attributed to mother and } \\
\text { debris particles. average of } \mathrm{R}^{-} \text {and } \mathrm{R}^{+}\end{array}$ & - \\
\hline $\mathrm{R}_{\max }$ & maximum extent of breakage attributable to chipping & - \\
\hline $\mathrm{R}_{\text {cum }}$ & cumulative extent of breakage & - \\
\hline $\mathrm{r}$ & attrition rate & $\mathrm{g} \mathrm{s}^{-1}$ \\
\hline$\Delta \mathrm{v}_{\mathrm{p}}$ & Particle impact relative velocity & $\mathrm{m} \mathrm{s}^{-1}$ \\
\hline $\mathrm{v}_{\mathrm{p}}$ & particle impact velocity & $\mathrm{m} \mathrm{s}^{-1}$ \\
\hline $\mathrm{V}_{\mathrm{p} 0}$ & particle transition velocity from no breakage to breakage & $\mathrm{m} \mathrm{s}^{-1}$ \\
\hline \multicolumn{3}{|c|}{ Greek letters } \\
\hline$\alpha_{\mathrm{Ar}}$ & Archard fitting constant & $\mathrm{m}^{-3}$ \\
\hline$\alpha_{\mathrm{G} \& \mathrm{Z}}$ & Ghadiri \& Zhang fitting constant & $\mathrm{kg}^{-1} \cdot \mathrm{m}^{-0.5} \cdot \mathrm{s}^{2}$ \\
\hline$\eta_{\mathrm{c}}$ & Collision efficiency factor & - \\
\hline$\rho_{\mathrm{p}}$ & particle density & $\mathrm{kg} \mathrm{m}^{-3}$ \\
\hline$\theta$ & angle of impact & $\circ$ \\
\hline$\Delta \mathrm{s}$ & sliding distance & $\mathrm{m}$ \\
\hline$\tau$ & residence time & $\mathrm{S}$ \\
\hline \multicolumn{3}{|c|}{ Abbreviation } \\
\hline CLC & Chemical Looping Combustion & \\
\hline F-CLC & Fresh CLC particles & \\
\hline PP & refers to particle-particle interactions & \\
\hline PW & refers to particle-wall interactions & \\
\hline W F-CLC & Washed fresh CLC particles & \\
\hline SPIT & Single particle impact test & \\
\hline SIT & Scirocco impact test & \\
\hline G\&Z & Ghadiri \& Zhang & \\
\hline $\mathrm{Ar}$ & Archard & \\
\hline $\mathrm{i}$ & refers to a region & \\
\hline
\end{tabular}




\section{INTRODUCTION}

Fluidised beds and circulating fluidised beds are widely used for carrying out heterogeneous catalytic reactions in which the solid catalyst particles need to be regenerated in order to be reprocessed. The circulation of the solids subjects them to mechanical stresses causing attrition. The fines that are generated in this way pose significant process problems and considerable material losses. Zenz [1] identifies the most stressful regions in a fluidised bed, where the mechanical stresses lead to particle attrition, as the gas distributor jets, bubbling bed, cyclones and bends. He also suggests that each of these sources of attrition should be analysed individually, due to the different mechanisms of attrition involved, such as surface abrasion, chipping and fragmentation. The predominance of any of these mechanisms is affected by a combination of particle properties and process operating conditions as well as the geometry of the unit [2]. The cyclone is one of the most significant contributors to particle attrition especially at high superficial gas velocities [3]. Particles entering the cyclone at high velocities are likely to impact on the opposite side of the inlet duct, and slide against the wall towards the bottom outlet. Usually particle attrition in cyclones is by surface abrasion/chipping, but whenever a certain threshold velocity is exceeded then fragmentation can also take place. Werther et al. [4] developed a model of cyclone-induced particle attrition under conditions of surface abrasion for the Fluid Catalytic Cracking (FCC) catalyst particles. They reported that the attrition rate was dependent on the material properties, gas kinetic energy, and particle size and inversely proportional to the square root of the particle loading due to the 'cushioning' effect. Reppenhagen et al. [5] examined the validity of the model by testing nine different cyclone geometries. Their model is based on pure abrasion but, as noted 
by Werther et al. [6], if the inlet velocity is increased and/or the particle loading decreased, particles will undergo severe chipping and/or fragmentation especially in case of fresh catalysts, which very often have some mechanical weaknesses like surface asperities, inhomogeneity of the matrix, etc.. However, in normal operations, conditions leading to severe particle attrition are usually avoided by using an appropriate design of the cyclone. Nevertheless, the development of a model that can predict the extent of attrition is highly desirable. It is critical to understand the conditions under which a certain mechanism of attrition is dominant. The particle dynamics in a cyclone is the key to understanding this phenomenon. Chu et al. [7] carried out a CFD-DEM analysis of the gas-solids flow in a cyclone, showing that the loading of particles can affect the particle trajectory pattern as well as the magnitude of interparticle and particle-wall interactions, the latter being dominant for particle loading less than $0.5 \mathrm{~kg}_{\text {Solid }} / \mathrm{kg}_{\text {Air }}$. In such cases, for instance, particle collisions against the wall of the cyclone can be the main cause of attrition. Reppenhagen et al. [5] confirmed that particle attrition in cyclones is the consequence of high velocity collisions at the entrance against the wall by looking at the erosion of a black-leaded film on the inner wall of a cyclone. Additionally, particles are also inevitably subjected to shear along the cyclone wall.

For a given solids loading, factors that contribute to cyclone attrition are the cyclone fluid dynamics, which dictates the particle velocity and residence time and the particle physical properties which influence the dependence of attrition on the operating conditions. Coupling the dynamics of particle motion with a single particle breakage model can give an estimate of the cyclone attrition, as proposed by Ghadiri et al. [8] for predicting the attrition of FCC particles induced by a single jet in a fluidised bed. This work aims to emulate this approach by obtaining the particle dynamics in a cyclone by a four-way-coupling CFD-DEM simulation. The impact breakage of crushed manganese oxide particles, intended for use in the 
Chemical Looping Combustion (CLC) process, is evaluated experimentally by single particle impact testing in order to develop a single particle breakage model that is used, along with the model of surface wear of Archard [9], to calculate the overall particle attrition in a cyclone.

The calculation is performed in the simulation post-processing stage using the time-averaged values of the frequency of particle-wall and particle-particle collisions, the particle relative impact velocity, the number of collisions per particle, the normal compressive force acting on the particles and the particle sliding distance along the wall per region of interest of the cyclone. The cyclone is partitioned into 10 regions of interest for particle motion in order to predict attrition locally.

As stated above, the test material is made of crushed manganese oxide particles intended for use as oxygen carrier for the CLC process. An impact breakage model is developed for a wide range of particle impact velocities and for different size cuts based on the single particle impact test method [10], thereafter referred to as 'SPIT', and by the Scirocco Impact Test method [11], termed as 'SIT'. The outcomes of the two tests are combined and a single particle attrition model is presented based on the theoretical chipping model of Ghadiri and Zhang [12].

\section{MATERIAls AND Methods}

The material, provided by IFP Energies Nouvelles in Solaize, France, consists of a batch of fresh natural manganese ores crushed for use as CLC oxygen carriers which will be denoted as F-CLC (i.e. fresh CLC particles). The particle size distribution (PSD) is wide and the particle shape is irregular as shown in Figure 1. The particle envelope density is $3300 \mathrm{~kg} / \mathrm{m}^{3}$. The PSD is evaluated gravimetrically by sieving using German standard DIN 4188 sieves. The five most representative size cuts of the distribution are chosen for impact testing to establish the effect of particle size. The material is very dusty as shown in Figure 1. In fact, 
dust readily adheres to particles and this affects the breakage results, as it contributes to the mass of debris. Therefore, before the tests, in order to get rid of these fines, the powder is 'washed' by wet sieving using water, which does not dissolve manganese oxide, and later on dried in an oven. Later experimental inspection showed no weakening of the particles due to washing as its breakability is slightly lower than that of the non-washed material. The washed material is termed as W F-CLC.

The two impact test methods, i.e. single particle impact test (SPIT) [10] and Scirocco impact test (SIT) [11] allow the particle extent of breakage to be correlated with its impact velocity. Generally, the extent of breakage is defined as the ratio of the mass of fines produced by attrition to the total mass of particles. Moreover, the theoretical model of Ghadiri and Zhang [12] for chipping of semi-brittle materials is used to model the experimental data. Further single particle impact tests are carried out on the 'non-washed' powder, F-CLC, and also used to investigate the effect of angle of impact.

In parallel, a CFD-DEM simulation of a small scale Stairmand cyclone is performed using EDEM $^{\mathrm{TM}}$ and ANSYS Fluent software packages (DEM Solutions, Edinburgh) to evaluate the fluid-particle interactions therein.
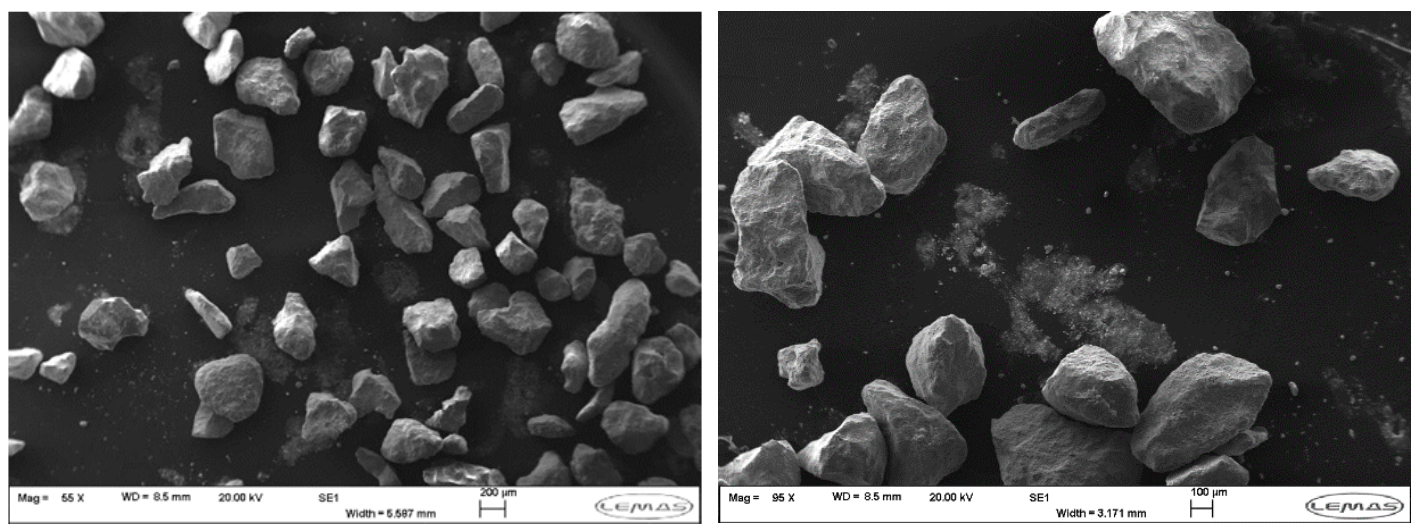

Figure 1. Scanning Electron Micrograph of crushed manganese particles used as test material

In the post-processing analysis the time-averaged values of the frequency of particle-wall and 
particle-particle collisions, velocity and angle of collisions, the number of collision per particle, compressive force acting on the particles and sliding distance are calculated. The cyclone is partitioned into 10 regions, where the dominant particle dynamics, i.e. collision or sliding against the wall is identified. The above-mentioned parameters are then obtained for each of these regions. Combining them with the experimental model of impact breakage and the abrasive model of Archard [9] allows the extent of particle attrition to be predicted.

\subsection{Particle Size Distribution}

The particle size distribution of F-CLC is evaluated by mechanical sieving and reported in Figure 2. The material is first split to get a small representative sample, sufficient for sieving, and avoiding errors due to segregation by size due to transportation of the initial large batch.

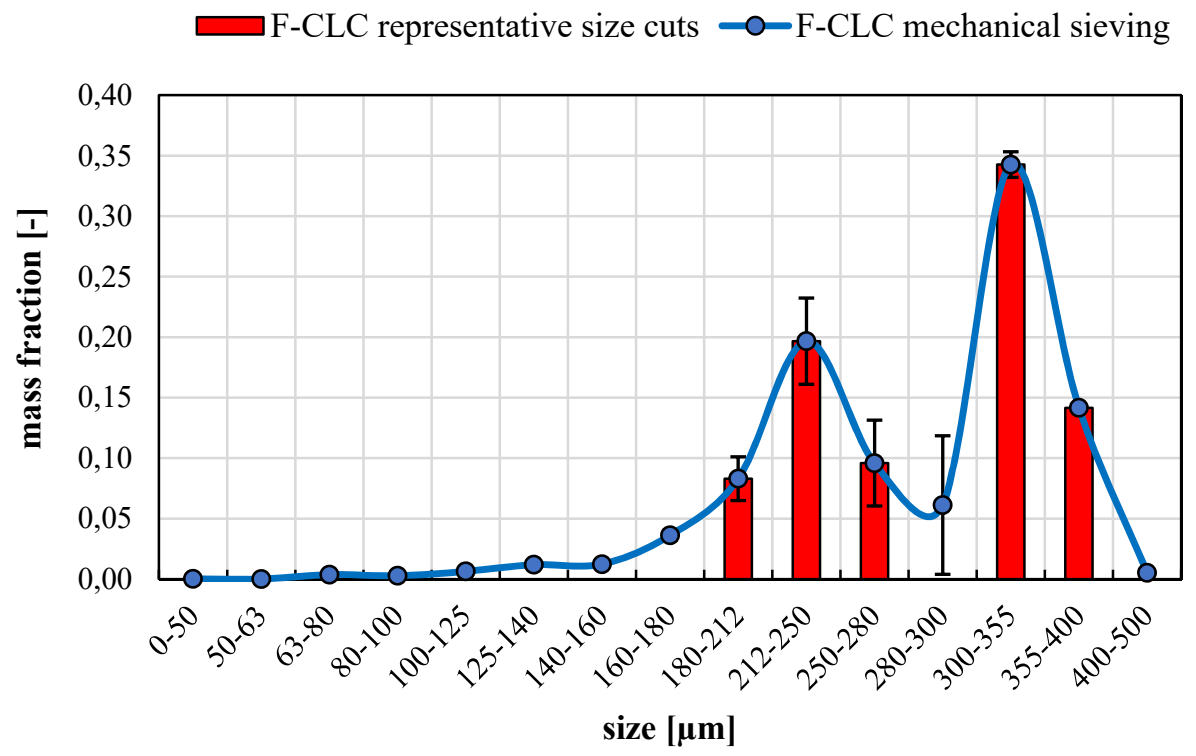

Figure 2. Particle Size Distribution of fresh CLC particles by mechanical sieving and most representative size cuts used for experimental analysis (in red)

The most representative size cuts are chosen to carry out the impact tests, they are: 180-212, 212-250, 250-280, 300-355 and 355-400 $\mu \mathrm{m}$. 


\subsection{Breakage Analysis}

Erosive and abrasive wear are two mechanisms of small-scale surface material removal. The former results from particle collisions, and the latter from particle sliding or rolling. The particle collisional breakage is analysed experimentally for F-CLC and W F-CLC particles by two different techniques: SPIT (single particle impact test) [10] and SIT (Scirocco disperser) [11].

The procedure for calculating the extent of breakage is described below in equations 2-4. Due to potential loss of particles during handling and testing, there is some uncertainty in estimating the actual extent of breakage. So upper and lower limits of breakage can be defined as follows. The initial mass of material, $\mathrm{m}_{0}$, is equal to:

$\mathrm{m}_{0}=\mathrm{m}_{\mathrm{m}}+\mathrm{m}_{\mathrm{de}}+\mathrm{m}_{\text {loss }}$

where $\mathrm{m}_{\mathrm{m}}$ is the collected mass of mother particles, $\mathrm{m}_{\mathrm{de}}$ is the collected mass of debris and $\mathrm{m}_{\text {loss }}$ is the mass loss.

Ghadiri and Zhang [10] define the extents of breakage as $\mathrm{R}^{-}, \mathrm{R}^{+}$and $\mathrm{R}^{*}$ for the cases in which the losses are attributable to mother particles, debris or neglected. In the last case, the relative contributions of the mother particles and debris to the losses are uncertain, so $\mathrm{R}^{*}$ is based on the collected material after the impact test.

$$
\begin{aligned}
& \mathrm{R}^{-}=\frac{\mathrm{m}_{\mathrm{de}}}{\mathrm{m}_{0}} \\
& \mathrm{R}^{+}=\frac{\mathrm{m}_{0}-\mathrm{m}_{\mathrm{m}}}{\mathrm{m}_{0}} \\
& \mathrm{R}^{*}=\frac{\mathrm{m}_{\mathrm{de}}}{\mathrm{m}_{\mathrm{de}}+\mathrm{m}_{\mathrm{m}}}
\end{aligned}
$$

In practice $\mathrm{R}^{*}$ is close to $\mathrm{R}^{-}$and for the case in which the losses are small, the gap between $\mathrm{R}^{-}$ and $\mathrm{R}^{+}$is small. Since the SPIT and SIT methods have different degrees of losses, in this work 
the average of $\mathrm{R}^{-}$and $\mathrm{R}^{+}$, denoted as $\mathrm{R}_{\text {avg }}$, is used.

Mother particles and debris are collected after the test and separated using a sieve, the size of which is two standard sieve sizes below the lower limit of the feed particle size; e.g. the debris originating from breakage of particles of sieve cut, $\mathrm{d}_{0}=355-400 \mu \mathrm{m}$, is separated using a sieve with a mesh size of $d_{s}=300 \mu \mathrm{m}$. This technique has been widely used to quantify particle breakage by chipping when the debris is much smaller in size than the mother particles, so that the choice of the sieve size is actually not critical in the determination of the mass of debris $[13$,

14]. Naturally, this method is only valid up to the point where the size of mother particles $d_{m}$ decreases to a critical size $d_{m, m i n}$, which is equal to the size of the sieve opening $d_{s}$ of the sieve used for separating the debris from the mother particles as shown in Figure 3.

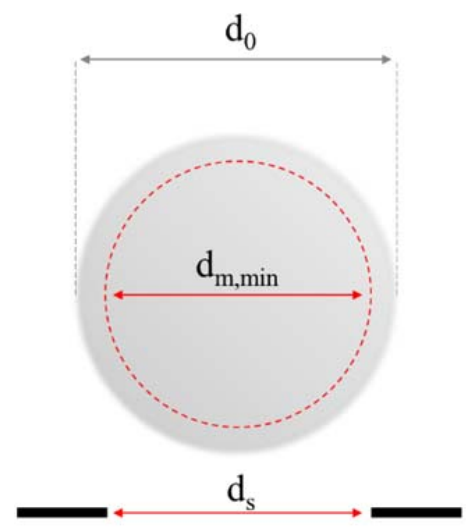

Figure 3. Schematic representation of the limit of the separation between mother particles and debris

The extent of breakage under these conditions is referred to as $\mathrm{R}_{\max }$ and, considering spherical particles, can be calculated as follow:

$\mathrm{R}_{\max }=\frac{\mathrm{m}_{\mathrm{de}, \max }}{\mathrm{m}_{0}}=\frac{\mathrm{m}_{0}-\mathrm{m}_{\mathrm{m}, \text { min }}}{\mathrm{m}_{0}}=1-\frac{\mathrm{m}_{\mathrm{m}, \min }}{\mathrm{m}_{0}}=1-\left(\frac{\mathrm{d}_{\mathrm{m}, \min }}{\mathrm{d}_{0}}\right)^{3}=1-\left(\frac{\mathrm{d}_{\mathrm{s}}}{\mathrm{d}_{0}}\right)^{3}$

Beyond this theoretical limit there is no more distinction between mother particles and debris. $\mathrm{R}_{\max }$ is then the maximum value of the extent of breakage for which the above approach can 
be used for describing the extent of breakage by chipping. On the other hand, it can also be seen as the threshold from chipping to fragmentation, which occurs when the particle breaks into several pieces of comparable sizes or at least when there is no clear distinction between mother particle and the rest. $\mathrm{R}_{\max }$ is shown in Table 1 for all the size cuts used in this work.

Table 1. Cut-off sieve sizes used for mother particles-debris separation for F-CLC

\begin{tabular}{|c|c|c|c|c|c|}
\hline $\begin{array}{c}\text { CLC size cuts } \\
{[\mu \mathrm{m}]}\end{array}$ & $355-400$ & $300-355$ & $250-280$ & $212-250$ & $180-212$ \\
\hline $\begin{array}{c}\text { cut-off sieve size } \\
{[\mu \mathrm{m}]}\end{array}$ & 300 & 250 & 212 & 180 & 150 \\
\hline $\mathrm{R}_{\max }[-]$ & 0.39 & 0.42 & 0.39 & 0.38 & 0.42 \\
\hline
\end{tabular}

The experimental data are fitted according to the chipping model of Ghadiri and Zhang [12] for semi-brittle material failure mode, given by equation 6 .

$$
\mathrm{R}_{\mathrm{G \& Z}}=\alpha_{\mathrm{G} \& \mathrm{Z}} \frac{\mathrm{H}}{\mathrm{K}_{\mathrm{c}}^{2}} \rho_{\mathrm{p}} \mathrm{d}_{\mathrm{p}} \mathrm{v}_{\mathrm{p}}^{2}
$$

where $\alpha_{\mathrm{G} \& \mathrm{Z}}$ is a proportionality constant, $\mathrm{H}$ and $\mathrm{K}_{\mathrm{c}}$ are respectively hardness and fracture toughness, $\rho_{p}$ is the particle density, $d_{p}$ is the particle size and $v_{p}$ the particle impact velocity. As for the abrasive wear due to particles sliding against the wall of the cyclone, the model of Archard is used which relates the extent of breakage, $\mathrm{R}_{\mathrm{Ar}}$, to the hardness of the particle $\mathrm{H}$, its sliding distance $\Delta \mathrm{s}$, normal compressive force acting on it, $\mathrm{F}_{\mathrm{n}}$, and a proportionality constant $\alpha_{\mathrm{Ar}}$.

$$
\mathrm{R}_{\mathrm{Ar}}=\alpha_{\mathrm{Ar}} \frac{\mathrm{F}_{\mathrm{n}} \Delta \mathrm{s}}{\mathrm{H}}
$$

$\Delta s$ and $F_{n}$ are obtained for each contact from outputs of the simulation. The hardness, $H$, is evaluated experimentally for several CLC particles using the nano-indentation technique. The Berkovich indenter is used at the loading rate of $5 \mathrm{mN} / \mathrm{s}$ for maximum loads of 25,50 and 75 $\mathrm{mN}$. $\mathrm{H}$ is found to be equal to $5.2 \mathrm{GPa}$ with a coefficient of variation of $9 \%$. No experimental 
data are available for wear due to particle sliding. So, considering the scale of the group $\frac{F_{n} \Delta s}{H}$ , the proportionality constant $\alpha_{\mathrm{Ar}}$ is chosen to have a value $\left(10^{12}\right)$ such that $\mathrm{R}_{\mathrm{Ar}}$ is comparable in magnitude with $R_{G \& Z}$. This is obviously arbitrary, but the main focus here is on the development of methodology. Realistic values are material dependent.

\subsubsection{Single Particle Impact Test (SPIT)}

The SPIT is carried out according to the procedure described by Ghadiri et al. [8].

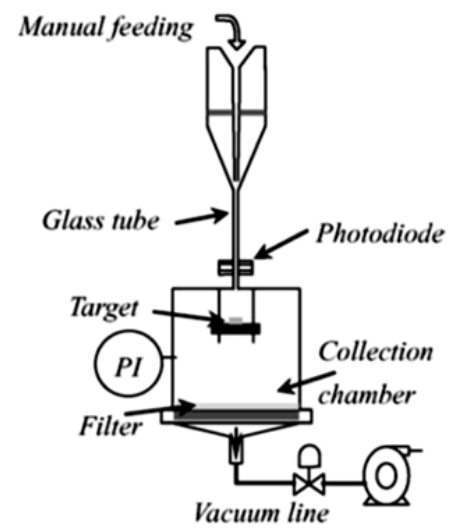

Figure 4. Schematic of the Impact test rig, [8]

As shown in Figure 4, the particles impact against a target of sapphire while their velocities are monitored. The tests are carried out at impact velocities of about $1.5 \mathrm{~m} / \mathrm{s}$ (free fall), 8,14 , 20 and $26 \mathrm{~m} / \mathrm{s}$. In order to shed light on the effect of impact angle $\theta$, inclined targets with angles of $30^{\circ}, 45^{\circ}$ and $60^{\circ}$ as shown in Figure 5 are also used.

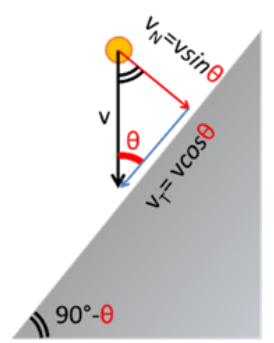

Figure 5. Angle of Impact 
F-CLC and W F-CLC particles are both used to characterise the extent of breakage as a function of size and impact velocity, while F-CLC of 355-400 $\mu \mathrm{m}$ size cut is also furtherly used to analyse the effect of impact angle. The following impact velocities are used for all tests: $2,8,14,20,26 \mathrm{~m} / \mathrm{s}$.

\subsubsection{Scirocco Impact Test (SIT)}

Scirocco is the dry disperser unit of Malvern Mastersizer 2000. Particles are fed and dispersed by an eductor using a high pressure nozzle operating in the range of 0.1 to 4 barg. Given the ' $L$ '-shape bend of the eductor, particles impact and experience stress causing attrition. Following passage through the disperser the particles are presented to the laser diffraction instrument for size measurement. They are then recovered downstream of the instrument by a plastic, axial cyclonic dust collector. The material is eventually collected and the extent of breakage characterised. The shift in PSD due to attrition can be obtained by both laser diffraction and gravimetric analysis. Given the design of the axial cyclone, the particles can avoid high velocity impacts at the entry. For this reason, its contribution to attrition is assumed to be far less than that caused by the high impact velocities achieved by SIT.

Varying the nozzle pressure from 0.1 to 4 barg for CLC particles, it is possible to achieve a range of impact velocity in Scirocco from 18 to $62 \mathrm{~m} / \mathrm{s}$, depending on their size. The experiments are performed on W F-CLC with the test details given in Table 2.

The particle velocity at the first impact in the Scirocco is calculated knowing the particle size, density and nozzle pressure, based on the correlation developed by Ali et al. [15], who simulated the gas-solid behaviour in Scirocco using Lagrangian particle tracking for the discrete phase and the Eulerian approach for the fluid. 
Table 2. Particle impact velocity as a function of size and pressure in the Scirocco disperser

\begin{tabular}{|c|ccccc|}
\hline \multicolumn{6}{|c|}{ Washed CLC particle velocity (W F-CLC) m/s } \\
\hline \multirow{2}{*}{ Particle Size [ $\boldsymbol{\mu m}]$} & \multicolumn{5}{c|}{ P [barg] } \\
\cline { 2 - 6 } & $\mathbf{0 . 1}$ & $\mathbf{1}$ & $\mathbf{2}$ & $\mathbf{3}$ & $\mathbf{4}$ \\
\hline $\mathbf{3 5 5 - 4 0 0}$ & 18.8 & 27.7 & $36.1 \mathrm{~m} / \mathrm{s}$ & $43.6 \mathrm{~m} / \mathrm{s}$ & $50.4 \mathrm{~m} / \mathrm{s}$ \\
\hline $\mathbf{3 0 0 - 3 5 5}$ & 19.6 & 28.9 & $37.6 \mathrm{~m} / \mathrm{s}$ & $45.4 \mathrm{~m} / \mathrm{s}$ & $52.5 \mathrm{~m} / \mathrm{s}$ \\
\hline $\mathbf{2 5 0 - 2 8 0}$ & 20.6 & 30.5 & $39.6 \mathrm{~m} / \mathrm{s}$ & $47.8 \mathrm{~m} / \mathrm{s}$ & $55.3 \mathrm{~m} / \mathrm{s}$ \\
\hline $\mathbf{2 1 2 - 2 5 0}$ & 21.3 & 31.5 & $40.5 \mathrm{~m} / \mathrm{s}$ & $49.4 \mathrm{~m} / \mathrm{s}$ & $57.1 \mathrm{~m} / \mathrm{s}$ \\
\hline $\mathbf{1 8 0 - 2 1 2}$ & 22.9 & 33.7 & $43.7 \mathrm{~m} / \mathrm{s}$ & $53.0 \mathrm{~m} / \mathrm{s}$ & $61.3 \mathrm{~m} / \mathrm{s}$ \\
\hline
\end{tabular}

\subsection{CFD-DEM Simulation of a Cyclone}

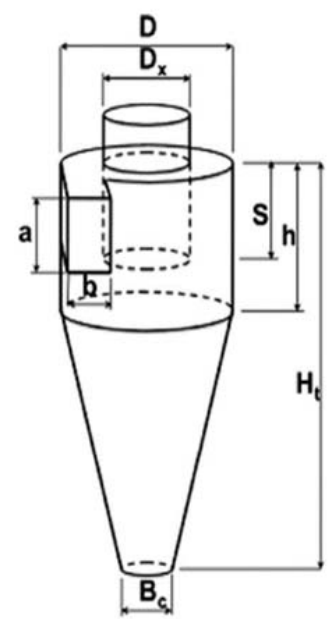

Figure 6. Dimensions of the cyclone

The CFD-DEM simulation of a cyclone is carried out by coupling ANSYS-Fluent with EDEM $^{\mathrm{TM}}$. DEM modelling is at the individual particle level, while the fluid flow by CFD is at the computational cell level. The four-way coupling allows the fluid forces to act on particles, particles interact with each other and react to and influence the fluid motion. At each time step, DEM gives the information such as velocities and positions of individual particles, for the evaluation of porosity and volumetric fluid-particles interaction forces in a computational cell. CFD uses them to determine the fluid flow field, which then yields the fluid forces acting on individual particles. The resulting forces are then incorporated into DEM, and individual particle motion is calculated in the next time step. The particle motion in turn affects the fluid phase, so that Newton's third law of motion is satisfied [16]. In this case, the fluid flow field 
is recalculated every 25 time steps of the DEM. A small scale Stairmand cyclone with tangential inlet style is used as the reference geometry in the simulation [17]. The dimensions, according to Figure 6, are reported in Table 3.

Table 3. Dimensions of the cyclone in $\mathrm{mm}$

\begin{tabular}{|ccccccccc|}
\hline Inlet & Inlet & Inlet & Cyclone & Dust & Cyclone & Cone & Vortex & Vortex \\
duct & depth & width & diameter & outlet & height & height & $\begin{array}{c}\text { finder } \\
\text { diameter }\end{array}$ & finder \\
length & & & & & & & & \\
\hline & $\mathrm{a}$ & $\mathrm{b}$ & $\mathrm{D}$ & $\mathrm{B}_{\mathrm{c}}$ & $\mathrm{H}_{\mathrm{t}}$ & $\mathrm{H}_{\mathrm{t}}$-h & $\mathrm{D}_{\mathrm{x}}$ & $\mathrm{S}$ \\
\hline 100 & 20 & 10 & 40 & 10 & 160 & 80 & 20 & 30 \\
\hline
\end{tabular}

The computational fluid domain contains 90,793 tetrahedron cells of average length of 1.35 mm. The Reynolds Stress Model (RSM) is used to solve the fluid-dynamics of the system as it gives the best agreement with experimental measurements [16, 17, 18]. The boundary conditions are set for the fluid entry and exit. Air enters the cyclone at $40 \mathrm{~m} / \mathrm{s}$ while atmospheric pressure is set for both top and bottom outlets. The drag model for a single sphere is used. The particles are spheres of $755 \mu \mathrm{m}$ diameter and a density of $3300 \mathrm{~kg} / \mathrm{m}^{3}$. It should be noted that the particle size is not the actual one of the test material for which the experimental breakage data have been obtained. The use of such large particle size reduces the simulation time. However, as the effect of particle size is known from the impact breakage model, the extent of breakage for $755 \mu \mathrm{m}$ is used in the calculations. Other DEM parameters, i.e. the shear modulus, Poisson's ratio and coefficients of restitution, sliding friction and rolling friction are $0.1 \mathrm{GPa}$ and 0.25 and $0.5,0.5,0.01$, respectively. It should be noted that these are not the actual values for this specific material at hand, but rather typical values which are realistic. The number of particles generated per second at the inlet pipe is 4000 , with an initial velocity of $1 \mathrm{~m} / \mathrm{s}$, which results in a mass flow rate of $2.97 \mathrm{~g} \mathrm{~s}^{-1}$ and a solids to fluid mass ratio (solids loading) of $0.31 \mathrm{~kg}_{\text {solids }} / \mathrm{kg}_{\text {air }}$. The DEM integration time step 
is $1.5 \times 10^{-6} \mathrm{~s}$ for a total simulation time of $4 \mathrm{~s}$.

\section{RESULTS AND DISCUSSIONS}

\subsection{Impact breakage analysis results of Single Particle Impact Test (SPIT) and Scirocco Impact Test (SIT)}

Recalling the model of Ghadiri and Zhang [12], the experimental results, in terms of extent of breakage, are plotted versus $\rho_{\mathrm{p}} \mathrm{d}_{\mathrm{p}} \mathrm{v}_{\mathrm{p}}{ }^{2}$ in order to work out $\alpha_{\mathrm{G} \& \mathrm{Z}} \frac{\mathrm{H}}{\mathrm{K}_{\mathrm{c}}{ }^{2}}$. If a unification of the data points is achieved on a straight line, then $\alpha_{\mathrm{G} \& \mathrm{Z}} \frac{\mathrm{H}}{\mathrm{K}_{\mathrm{c}}{ }^{2}}$ is the slope of the line. It is regarded as a lumped parameter that takes account of the mechanical properties and represents the breakage propensity and is often referred to as 'breakability index'[12]. It allows a direct comparison of the breakability of different materials upon impact. For F-CLC particles the extents of breakage $R^{+}, R^{*}, R^{-}$for all tested size cuts are reported in Figure 7 , while the average value $\mathrm{R}_{\mathrm{avg}}$ is shown in Figure 8. Extent of breakage Ravg for F-CLC particles by the SPIT for all particle sizes plotted against $\rho$ pdpvp2

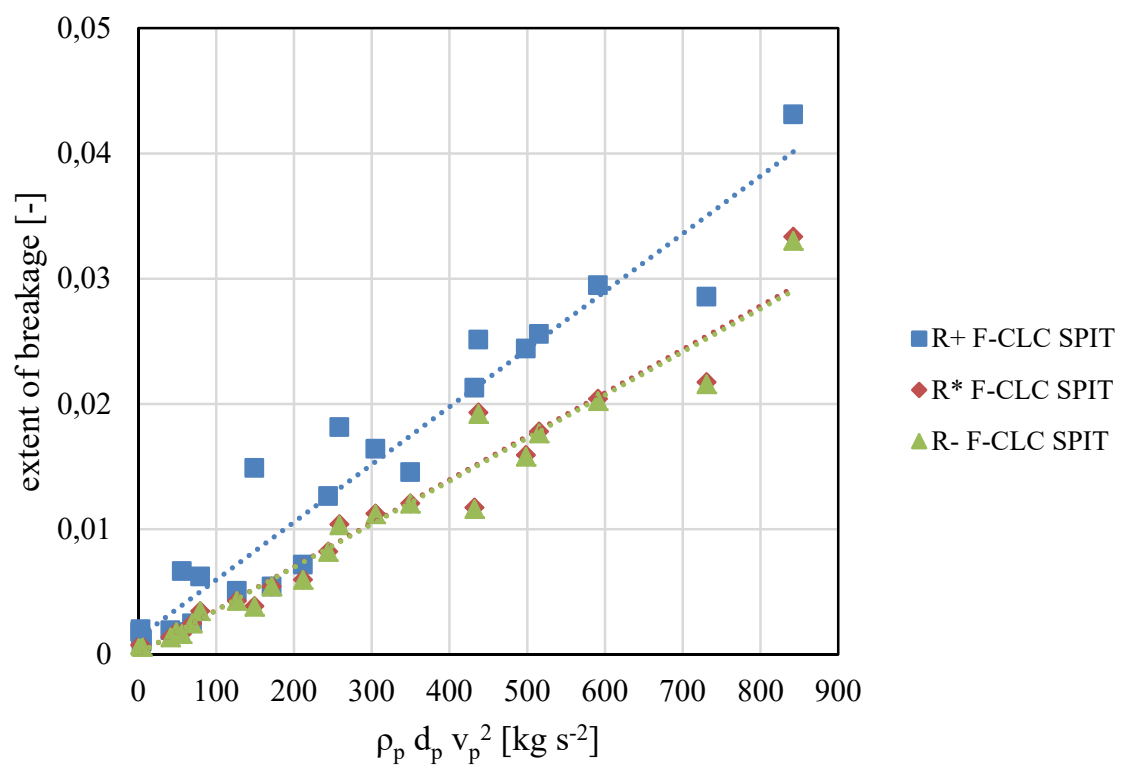

Figure 7. Extents of breakage R+, R* and R- for F-CLC particles by the SPIT for all sizes plotted against $\rho_{p} d_{p} v_{p}{ }_{p}^{2}$. 


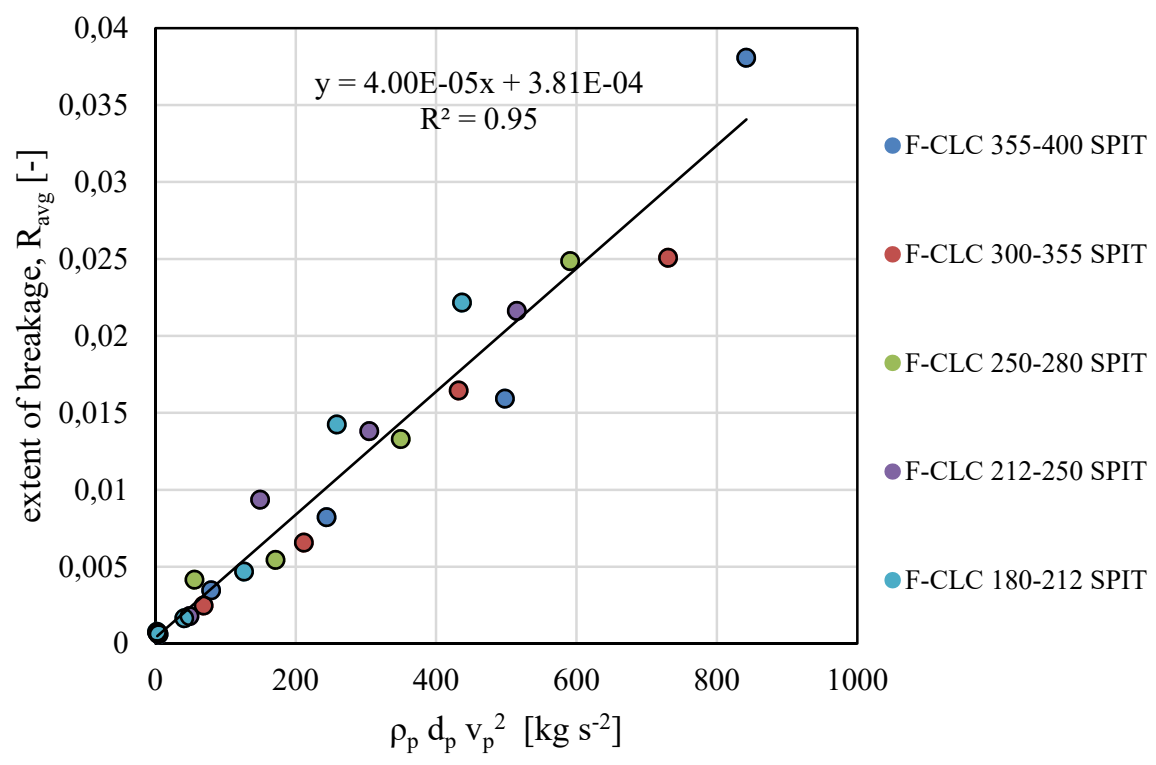

Figure 8. Extent of breakage $R_{a v g}$ for F-CLC particles by the SPIT for all particle sizes plotted against $\rho_{p} d_{p} v_{p}^{2}$

A good unification of the data points is achieved confirming the model takes proper account of particle size and impact velocity. It should also be noted that the maximum extent of breakage is around $4 \%$, which is well below $\mathrm{R}_{\max }$, supporting that observational evidence that particles undergo chipping. Further analysis on the effect of the angle of impact, $\theta$, indicates a simple linear dependency of the extent of breakage with the $\sin \theta$, as shown in Figure 9.

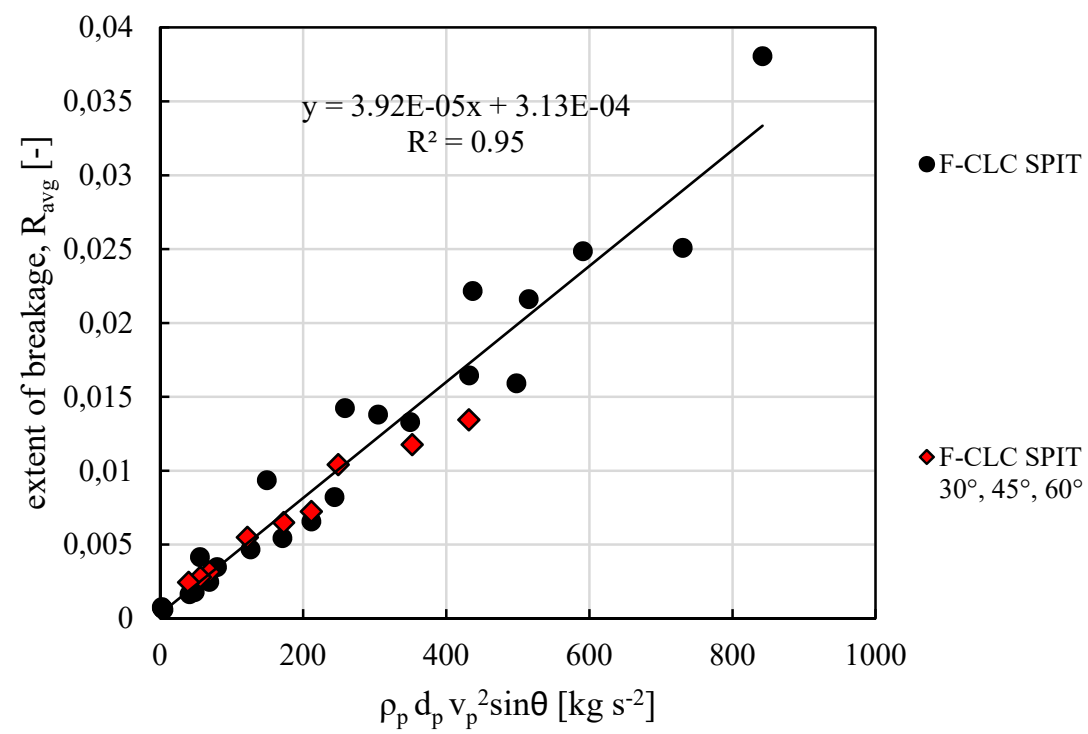

Figure 9. Extent of breakage R for F-CLC particles by the SPIT for all sizes and angles of impact plotted against $\rho_{\mathrm{p}} \mathrm{d}_{\mathrm{p}} \mathrm{v}_{\mathrm{p}}^{2} \sin \theta$ 
Remarkably, all the data points at normal and inclined impact lie on the same straight line. The model of Ghadiri and Zhang [12] is then modified to take account of the angle of impact empirically, as shown below:

$$
\mathrm{R}_{\mathrm{G} \& \mathrm{Z}}=\alpha_{\mathrm{G} \& \mathrm{Z}} \frac{\mathrm{H}}{\mathrm{K}_{\mathrm{c}}^{2}} \rho_{\mathrm{p}} \mathrm{d}_{\mathrm{p}} \mathrm{v}_{\mathrm{p}}^{2} \sin \theta
$$

where $\left.\alpha_{\mathrm{G \& Z}} \frac{\mathrm{H}}{\mathrm{K}_{\mathrm{c}}^{2}}\right|_{\mathrm{F}-\mathrm{CLC}}$ is equal to $4.0 \times 10^{-5}$.

The transition impact velocity for a given particle size below which there is little/no breakage, $\mathrm{v}_{\mathrm{p} 0}$, can be calculated considering the intercept of the fitted line with abscissa, i.e. the coordinate point $\left(\rho \mathrm{d}_{\mathrm{p}} \mathrm{v}_{\mathrm{p} 0}{ }^{2}, 0\right)$. In this case $\rho \mathrm{d}_{\mathrm{p}} \mathrm{v}_{\mathrm{p} 0}{ }^{2}$ is negative and equal to $-3.81 / 0.40$. This would return a negative value of the square of transition velocity, which is not physically possible but is a sign that the breakage of non-washed material is a little overestimated, as the adhered dust comes off the particles too.

Therefore, the transition velocity is calculated instead from the results obtained for the 'washed' particles (W F-CLC). The results of W-F-CLC from SPIT and SIT are reported separately for all size cuts in terms of $\mathrm{R}^{+}, \mathrm{R}^{*}, \mathrm{R}^{-}$in Figure 10 and Figure 11, respectively. They are also put together and shown in Figure 12, where a remarkable unification is obtained. 


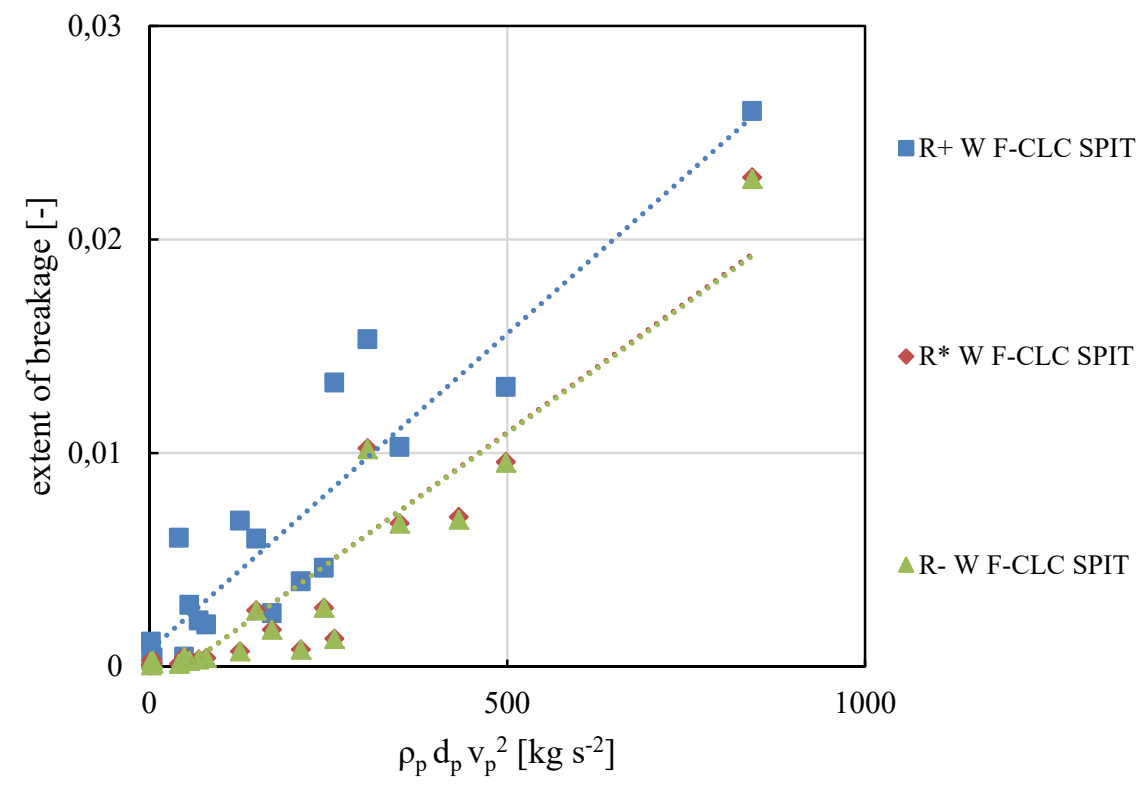

Figure 10. Extents of breakage R+, $\mathrm{R}^{*}$ and $\mathrm{R}$ - for $\mathrm{W}$ F-CLC particles by the SPIT for all the sizes plotted against $\rho_{\mathrm{p}} \mathrm{d}_{\mathrm{p}} \mathrm{v}_{\mathrm{p}}^{2}$.

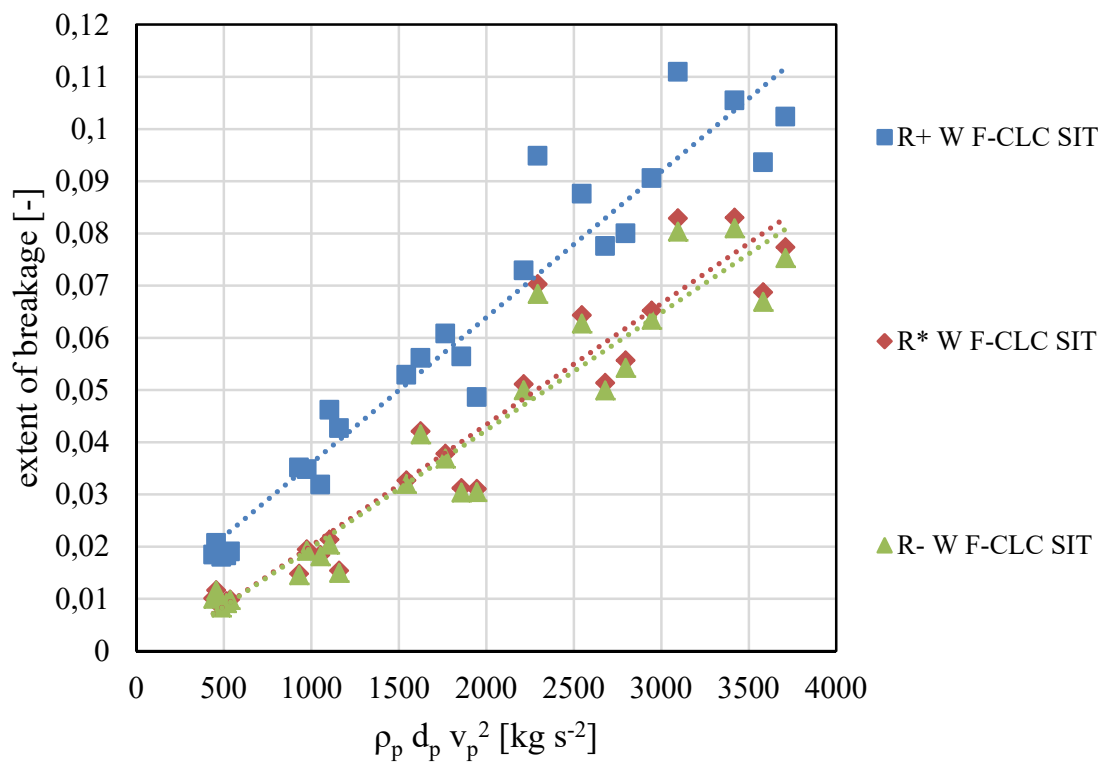

Figure 11. Extents of breakage R+, R* and R- for W F-CLC particles by SIT for all sizes plotted against $\rho_{\mathrm{p}} \mathrm{d}_{\mathrm{p}} \mathrm{v}_{\mathrm{p}}{ }^{2}$ 


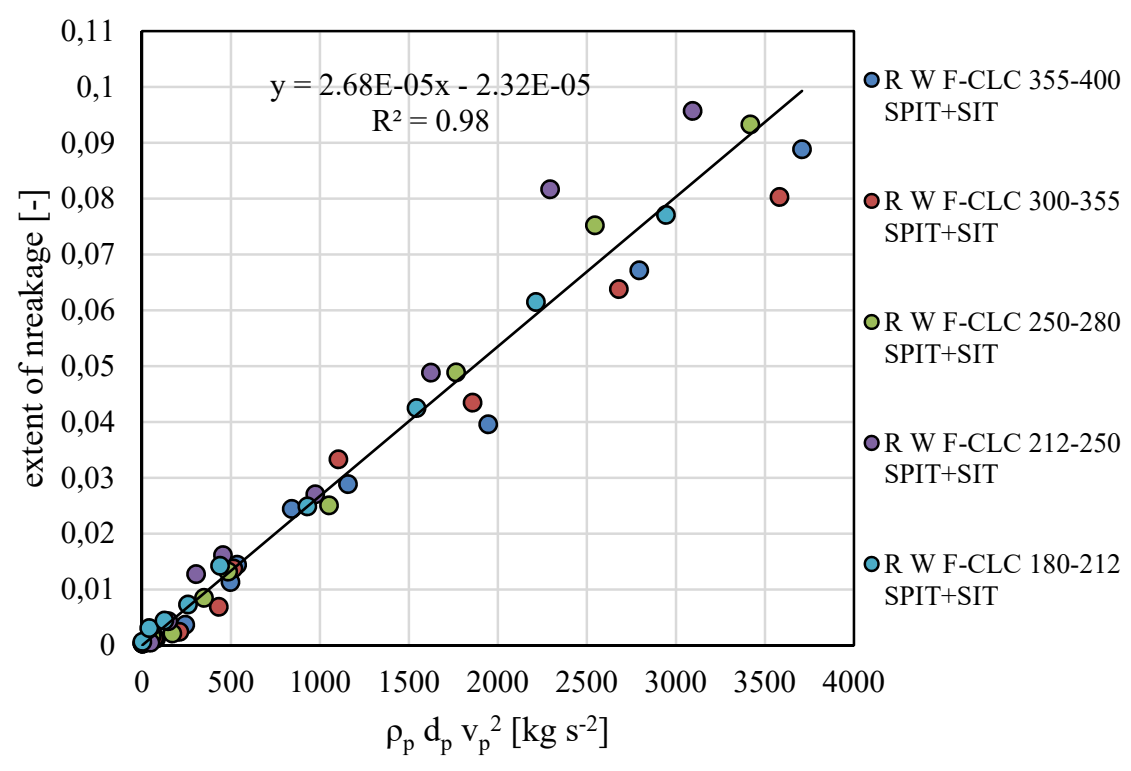

Figure 12. Extent of breakage R for W F-CLC particles by SPIT and SIT for each size plotted against $\rho_{p} d_{p} v_{p}{ }_{p}^{2}$

For the washed material $\left.\alpha_{\mathrm{G \& Z}} \frac{\mathrm{H}}{\mathrm{K}_{\mathrm{c}}{ }^{2}}\right|_{\mathrm{W} \text { F-CLC }}$ is equal to $2.68 \times 10^{-5}$. The transition velocity can be evaluated as a function of the breakability index, particle size and density as explained previously and according to the equation (9):

$\mathrm{v}_{\mathrm{p} 0}=\sqrt{\frac{2.32 \times 10^{-5}}{\alpha_{\mathrm{G} \& \mathrm{Z}} \frac{\mathrm{H}}{\mathrm{K}_{\mathrm{c}}^{2}} \rho_{\mathrm{p}} \mathrm{d}_{\mathrm{p}}}}$

By extension, the dependency on the angle of impact is implemented in the model for the 'washed' material, defining the extent of breakage as $\mathrm{R}_{\mathrm{W} \text { F-CLC: }}$

$\left\{\begin{array}{l}\mathrm{R}_{\mathrm{W} \text { F-CLC }}=\left.\alpha_{\mathrm{G} \& \mathrm{Z}} \frac{\mathrm{H}}{\mathrm{K}_{\mathrm{c}}^{2}}\right|_{\mathrm{W} \text { F-CLC }} \rho_{\mathrm{p}} \mathrm{d}_{\mathrm{p}} \mathrm{v}_{\mathrm{p}}^{2} \sin \theta \\ \mathrm{v}_{\mathrm{p}} \geq \mathrm{v}_{\mathrm{p} 0}\end{array}\right.$

The values of the transition velocities for the studied size cuts and the particle size, for a normal impact, are reported in Table 4. 
Table 4. Transition velocities at normal impact for different particle sizes, $\mathrm{v}_{\mathrm{p} 0}$, for given breakability index, $\alpha \frac{\mathrm{H}}{\mathrm{K}_{\mathrm{c}}^{2}}$ and intercept with the abscissa, $\rho \mathrm{d}_{\mathrm{p}} \mathrm{v}_{\mathrm{p} 0}{ }^{2}$ (extent of breakage $=0$ ), for W F-CLC.

\begin{tabular}{|c|c|c|}
\hline & \multicolumn{2}{|c|}{ W F-CLC } \\
\hline \multirow{3}{*}{ Particle size $[\mu \mathrm{m}]$} & $\alpha \frac{\mathrm{H}}{\mathrm{K}_{\mathrm{c}}^{2}}$ & $\rho d_{p} v_{p 0}^{2}$ \\
\hline & $2.68 \times 10^{-5}$ & 0.86 \\
\hline & \multicolumn{2}{|c|}{$\mathrm{v}_{\mathrm{p}_{0}}[\mathrm{~m} / \mathrm{s}]$} \\
\hline 755 (used for the simulation) & \multicolumn{2}{|c|}{0.59} \\
\hline $355-400$ & \multicolumn{2}{|c|}{0.83} \\
\hline $300-355$ & \multicolumn{2}{|c|}{0.89} \\
\hline $250-280$ & \multicolumn{2}{|c|}{0.99} \\
\hline $212-250$ & \multicolumn{2}{|c|}{1.07} \\
\hline $180-212$ & \multicolumn{2}{|c|}{1.16} \\
\hline
\end{tabular}

The impact of several particles of W F-CLC at free fall velocity (about $1.5 \mathrm{~m} / \mathrm{s}$ ) is analysed by using a high-speed camera, confirming that breakage occurs at such low impact velocities. A sequence of photos is reported below, showing breakage upon impact of a particle of 355-400 $\mu \mathrm{m}$ (Figure 13). A comparison of extents of breakage of F-CLC and W F-CLC is shown in the Appendix in Figure A1.
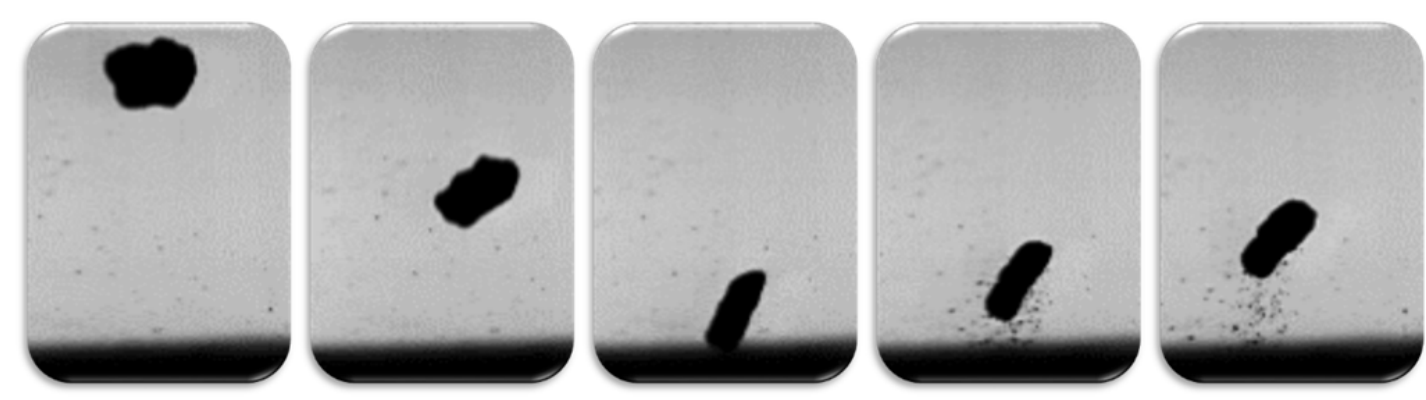

Figure 13. A W F-CLC particle breaking upon impact at $1.5 \mathrm{~m} / \mathrm{s}$

\subsection{CFD-DEM Simulation of a Cyclone}

A steady state CFD study of the fluid dynamics without particles is initially performed and compared with that obtained from the CFD-DEM simulation, where particles are also 
simulated. The axial, radial and tangential velocities for both cases are reported in Figure 14 for the y-plane containing the diameter with the coordinate system shown in the figure. The simulation time of $4 \mathrm{~s}$ corresponds to four times the average particle residence time.

a)

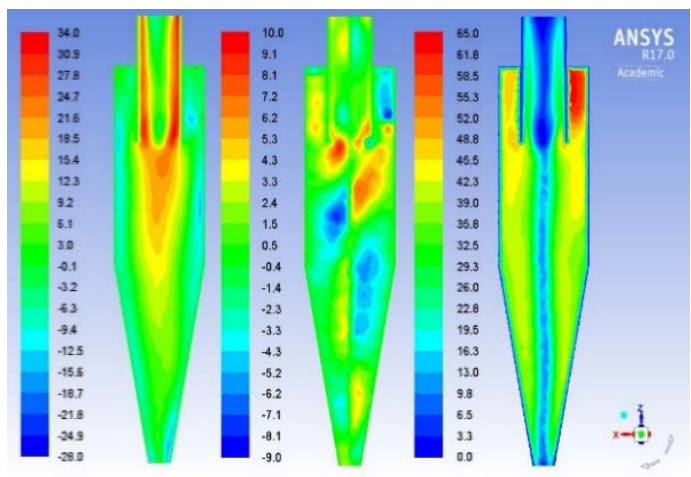

b)

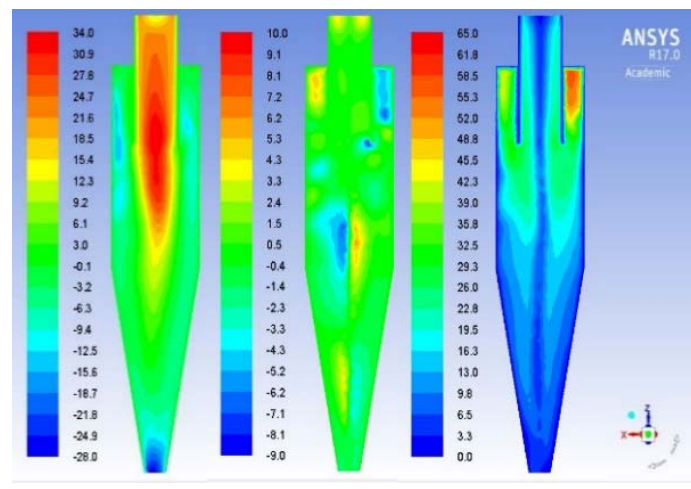

Figure 14. (a): axial, radial and tangential fluid velocities in the case of a steady state CFD simulation; (b): in the case of a transient CFD-DEM simulation at $4 \mathrm{~s}$

The fluid pattern is influenced by the presence of the solids phase. The tangential velocity is substantially decreased. This occurrence is confirmed experimentally by Yuu et al. [19]. The particle flow pattern at $4 \mathrm{~s}$ is shown in Figure 15. It is rather irregular, the more common strand regime is not reached as also shown by Wei et al. [20] for solid loadings less than 0.72 $\mathrm{kg}_{\text {solids }} / \mathrm{kg}_{\text {air }}$. Particles are accelerated to a maximum velocity of 3-4 m/s, in the inlet channel before entering the actual cyclone. They are then decelerated and start spiralling along the body of the cyclone, gradually descending towards the bottom outlet. 


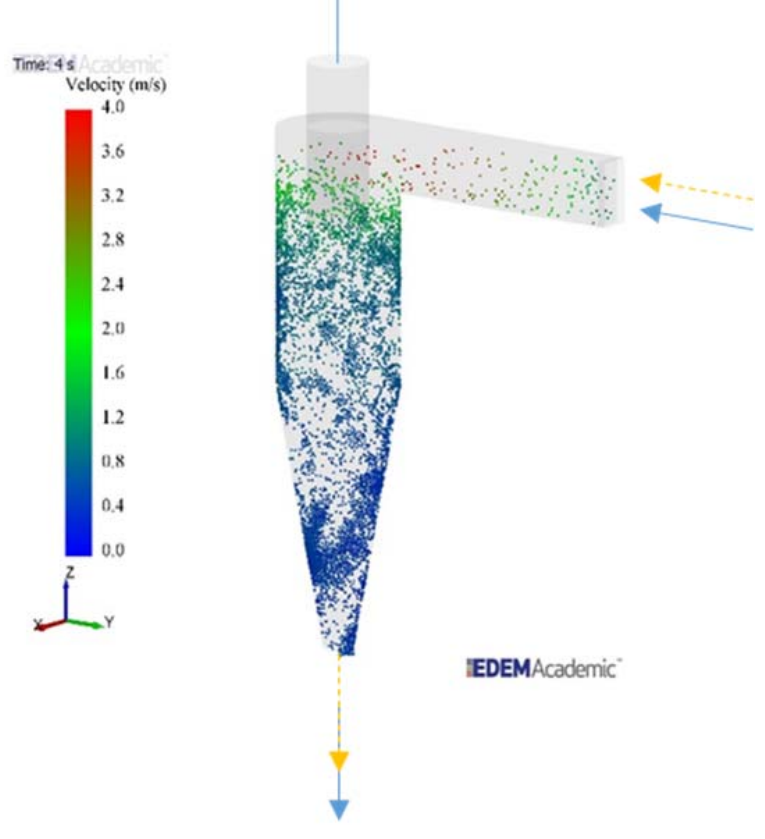

Figure 15. Solid pattern in the cyclone

The CFD-DEM simulation reveals the necessity of evaluating attrition locally as the particles experience high velocity impacts, mostly at the entrance, as well as shear thereafter. Attrition should therefore be analysed locally based on the current state of the particles, given by $\mathrm{EDEM}^{\mathrm{TM}}$ as the geometry of the cyclone is partitioned into 10 regions of interest, as shown in Figure 16. The information obtained by the software such as particle velocity, number of particles, particle displacement and normal compressive force are then used to work out the particle attrition occurring in each region. 


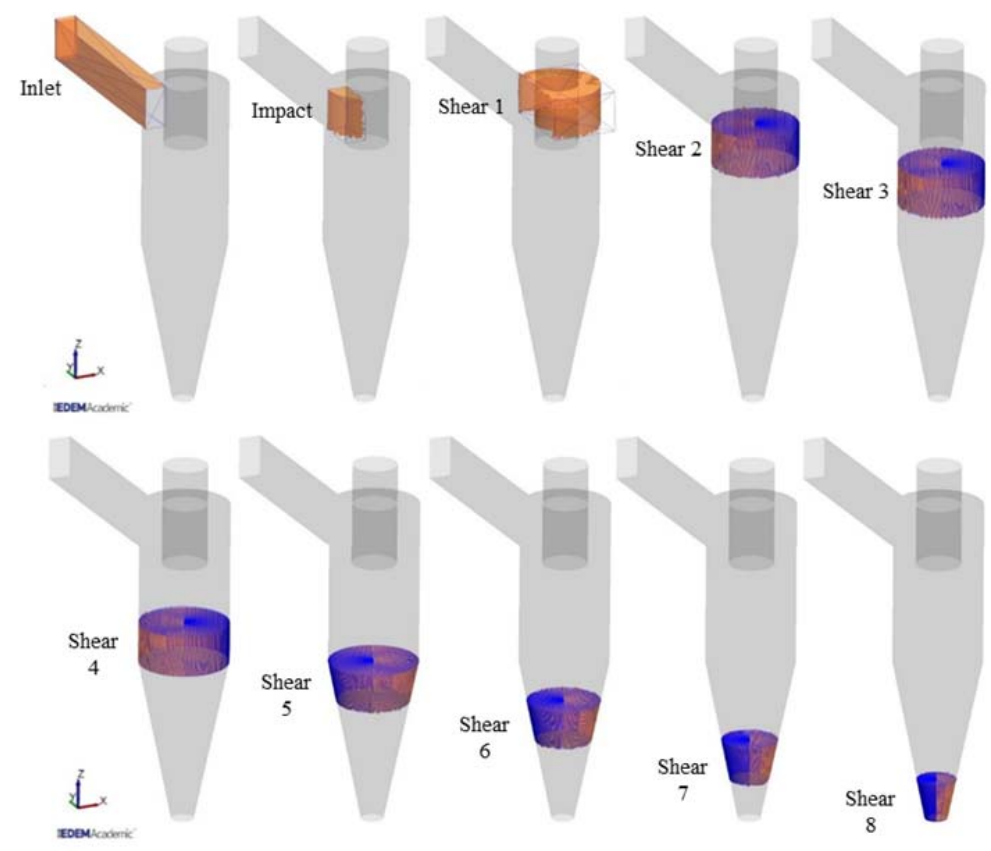

Figure 16. Regions of interest of the cyclone

Referring to Figure 16, the 'Inlet' is the region that corresponds to the feeding pipeline. In this region attrition is neglected as a result of minimum, perhaps null, inter-particle and wallparticle interaction.

In the region called 'Impact' particles collide at the highest velocity mainly against the wall of the cyclone. The particle attrition here, for both particle-wall and particle-particle collisions, is evaluated applying the model of chipping of Ghadiri and Zhang [12], $\mathrm{R}_{\mathrm{G} \& \mathrm{Z}}$, fitted to the experimental data. The regions "Shear 1" to "Shear 8" are all the same z-length as $20 \mathrm{~mm}$. Here, attrition is evaluated applying the abrasive wear model of Archard [9], $\mathrm{R}_{\mathrm{Ar}}$, given the tendency of particles shearing along the wall of the cyclone. In "Shear 1" collisional attrition is also evaluated, being a transition region.

\subsection{Cyclone attrition analysis}

Particle attrition is evaluated under steady state condition, i.e. the inlet solids flow rate is equal to outlet solids flow rate. This occurs after a time equal to the particle residence time; its time-averaged value is equal to $1.35 \mathrm{~s}$, implying a plug flow behaviour, while the time- 
averaged number of particles inside the cyclone is 5424, as shown in Figure 17.

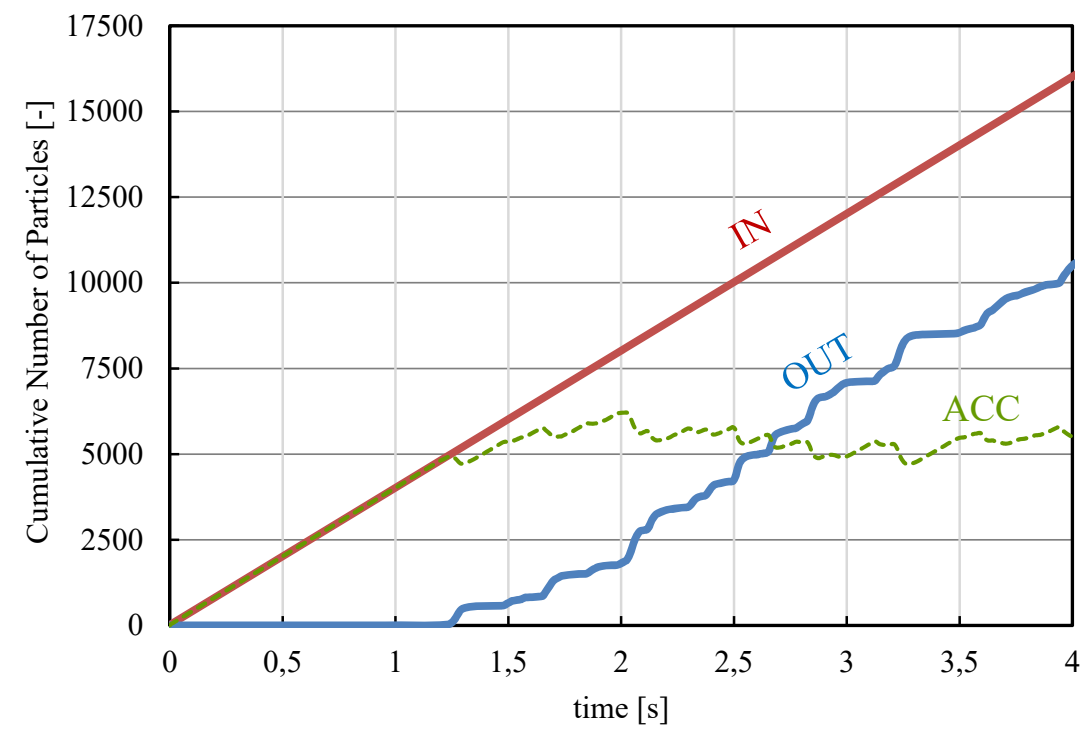

Figure 17. Cumulative number of particles versus time: INLET in red, OUTLET in blue and ACCUMULATION=IN-OUT in green

At steady state, the simulation returns the following time-averaged parameters per region ' $i$ ': the number of particles $\mathrm{N}_{\mathrm{pi}}$, the net flow of number of particles $\dot{\mathrm{N}}_{\mathrm{p}_{\mathrm{i}}}$, the number of particlewall and particle-particle collisions $\mathrm{N}_{\mathrm{ci}}$, the particle relative impact velocity $\Delta \mathrm{v}_{\mathrm{pi}}$, the particle velocity $\mathrm{v}_{\mathrm{p} i}$, the compressive normal force $\mathrm{F}_{\mathrm{ni}}$ and the angle of impact $\theta_{\mathrm{i}}$.

The extent of particle attrition (mass fraction of debris produced) in the "Impact" region, $\mathrm{R}_{\text {Impact, }}$ is evaluated as the summation of two contributions arising from particle-wall and particle-particle collisions, where the latter is calculated considering that an impact between two particles leads to the same breakage as of one particle impacting against a fixed target at their relative impact velocity:

$\mathrm{R}_{\text {Impact }}=\left.\left.\mathrm{R}_{\mathrm{W} \text { F-CLC }} \mathrm{N}_{\mathrm{c} / \mathrm{p}}\right|_{\mathrm{PW}} \eta_{\mathrm{c}}\right|_{\mathrm{PW}}+\left.\mathrm{R}_{\mathrm{W} \text { F-CLC }} \frac{\left.\mathrm{N}_{\mathrm{c} / \mathrm{p}}\right|_{\mathrm{PW}}}{2} \eta_{\mathrm{c}}\right|_{\mathrm{PP}}$

According to equation (11) $\mathrm{R}_{\mathrm{w}}$ F-CLC is the impact breakage model for W F-CLC particles computed using the relative particle-wall or particle-particle velocity and angle of impact, 
$\mathrm{N}_{\mathrm{c} / \mathrm{p}}$ is the number of collisions per particle and $\eta_{\mathrm{c}}$ is the collision efficiency factor (it takes into account the fact that some collision might not occur above the transition velocity).

$\mathrm{N}_{\mathrm{c} / \mathrm{p}}$ is calculated according to equation (12), as the ratio of the frequency of collision with the flow rate of number particles entering the "Impact" region; at steady state this is equal to that entering the cyclone $\left(4000 \mathrm{~s}^{-1}\right)$ :

$\mathrm{N}_{\mathrm{c} / \mathrm{p}}=\frac{\dot{\mathrm{N}}_{\mathrm{c}_{\text {Impact }}}}{\dot{\mathrm{N}}_{\text {plmpact }}}=\frac{\dot{\mathrm{N}}_{\mathrm{c}_{\text {Impact }}}}{\dot{\mathrm{N}}_{\mathrm{p}_{0}}}$

The frequency of collision in the "Impact" region is calculated as the total number of collisions, divided by the total time of observation, as shown in equation (13):

$\dot{\mathrm{N}}_{\mathrm{c}_{\text {Impact }}}=\frac{\mathrm{N}_{\mathrm{c}_{\text {Impact }}}}{\Delta \mathrm{t}}$

while $\eta_{c}$ is calculated according to equation (14) as the ratio of number of collisions above the transition velocity over the total number of collisions:

$\eta_{\mathrm{c}}=\frac{\left.\mathrm{N}_{\mathrm{c}_{\text {Im pact }}}\right|_{\Delta \mathrm{v}_{\mathrm{p}}>\mathrm{v}_{\mathrm{p} 0}}}{\mathrm{~N}_{\mathrm{c}_{\text {Im pact }}}}$

Collisional attrition is furthermore evaluated for the region "Shear 1" being a transition region between a collision dominant mechanism to surface abrasion.

On the other hand, particle attrition for the shearing regions $\mathrm{R}_{\text {shear }, \mathrm{i}}$ is evaluated as

$\mathrm{R}_{\text {shear }, \mathrm{i}}=\mathrm{R}_{\mathrm{Ar}, \mathrm{i}}$

Recalling the definition of Archard's model, the particle sliding distance against the wall, $\Delta \mathrm{s}_{\mathrm{i}}$, is calculated as:

$$
\Delta \mathrm{s}_{\mathrm{i}}=\tau_{\mathrm{i}} \mathrm{v}_{\mathrm{pi}}
$$

where $\tau_{\mathrm{i}}$ is the mother particle residence time per region, given by 


$$
\tau_{\mathrm{i}}=\frac{\mathrm{N}_{\mathrm{p}_{\mathrm{i}}}}{\dot{\mathrm{N}}_{\mathrm{p}_{\mathrm{i}}}}
$$

The time-averaged compressive force per particle and sliding distance are reported below in Figure 18, showing the maximum value in regions 'Shear 1' and 'Shear 3', respectively.

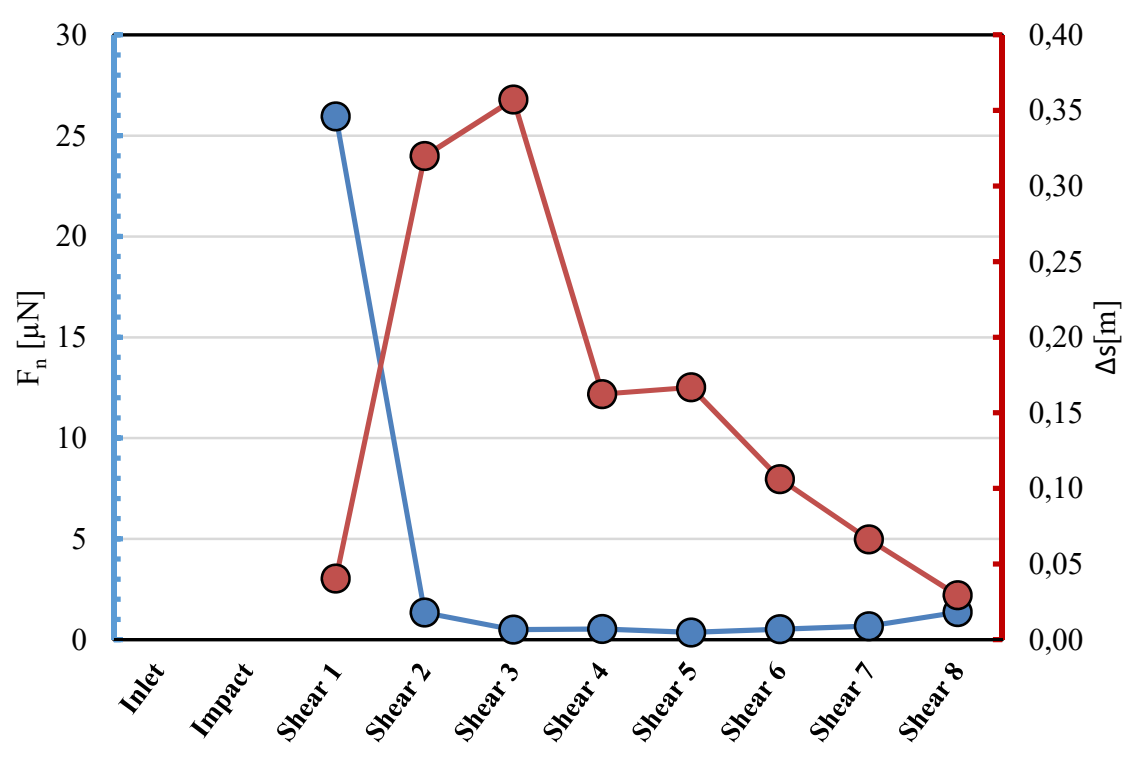

Figure 18. Compressive force per particle and sliding distance per region

All the values mentioned above are reported in the Appendix in Table A1 along with the extent of breakage per region $R_{i}$ and the cumulative extent of breakage $R_{\text {cum,i }}$, which is defined as

$$
\mathrm{R}_{\text {cum }, \mathrm{i}}=1-\prod_{\mathrm{i}=0}^{\mathrm{n}}\left(1-\mathrm{R}_{\mathrm{i}}\right) \square \sum_{\mathrm{i}=0}^{\mathrm{n}} \mathrm{R}_{\mathrm{i}}
$$

where ' $n$ ' is the number of regions.

In Figure 19 the extent of breakage per region $R_{i}$ and the cumulative extent of breakage $R_{\text {cum }}$ are plotted showing that the 'Impact' region along with the 'Shear 1' region provide together the largest contribution to attrition, about $81 \%$ of the total breakage. 


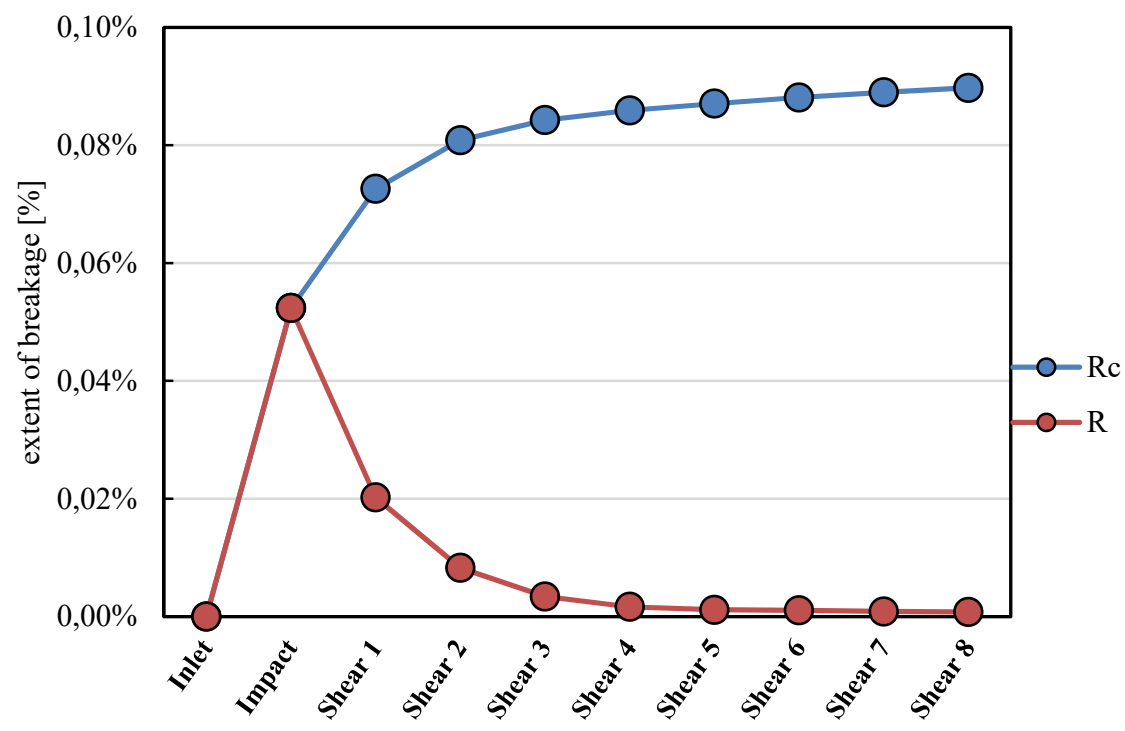

Figure 19. Local, $R$, and cumulative, $R_{\text {cum }}$, extent of breakage per region

Moreover, the particle size at each region, $\mathrm{d}_{\mathrm{pi}}$, is calculated as:

$\mathrm{d}_{\mathrm{p}, \mathrm{i}}=\mathrm{d}_{0}\left(1-\mathrm{R}_{\mathrm{cum}, \mathrm{i}}\right)^{1 / 3}$

and finally, the breakage rate per region, $r_{i}$, is according to the equation (21):

$\mathrm{r}_{\mathrm{i}}=\mathrm{m}_{\mathrm{i}-1} \dot{\mathrm{N}}_{\mathrm{p}, \mathrm{i}} \mathrm{R}_{\mathrm{i}}$

The particle size and the breakage rate at each region are reported in Figure 20.

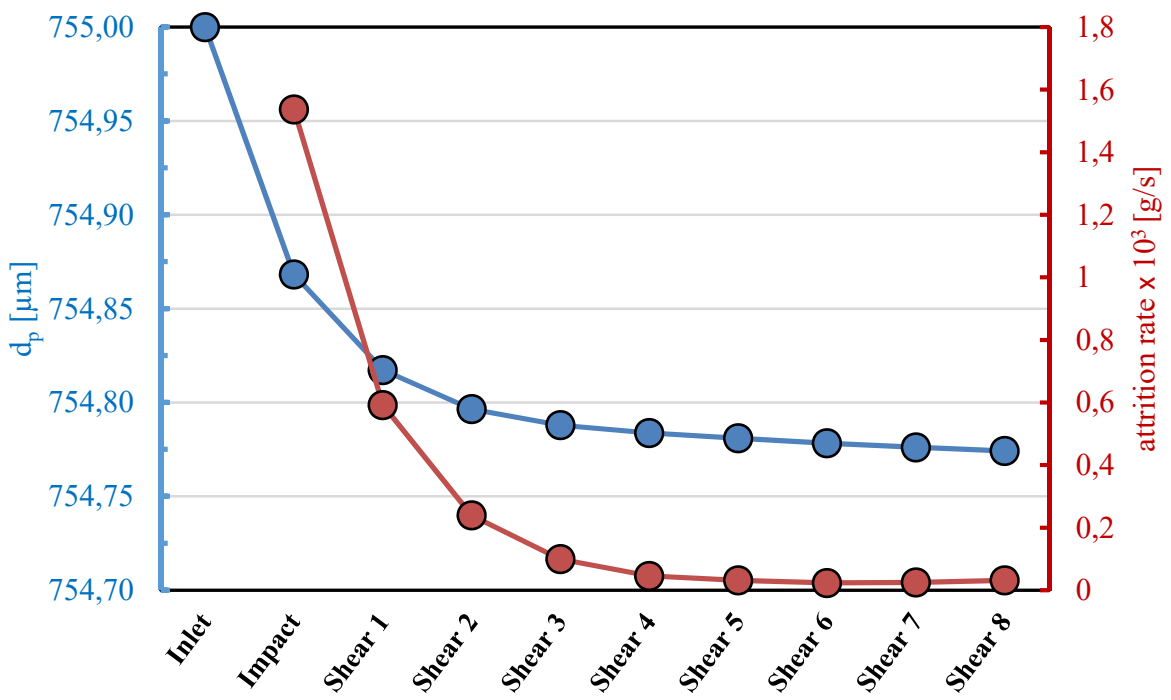

Figure 20. Particle size and attrition rate per region 
The figure shows an abrupt reduction in particle size related to the passage in the "Impact" region and the first shearing region, where the particle velocity is more important. Then a more gradual reduction as the particles head to the last shear region. It should be noted that these results are based on an arbitrary parameter for the Archard model, therefore no comparison with a real system can be made. However, the trend as well as the magnitude of particle attrition for this kind of system appears realistic: after one passage through the cyclone, the diameter of a particle is reduced only by $0.03 \%$ (from $755 \mu \mathrm{m}$ to $754.8 \mu \mathrm{m}$ ).

A more detailed analysis of the regions "Impact" and "Shear 1" is reported in Figure 21 and Table 5 in order to elucidate the underlying mechanism of attrition.

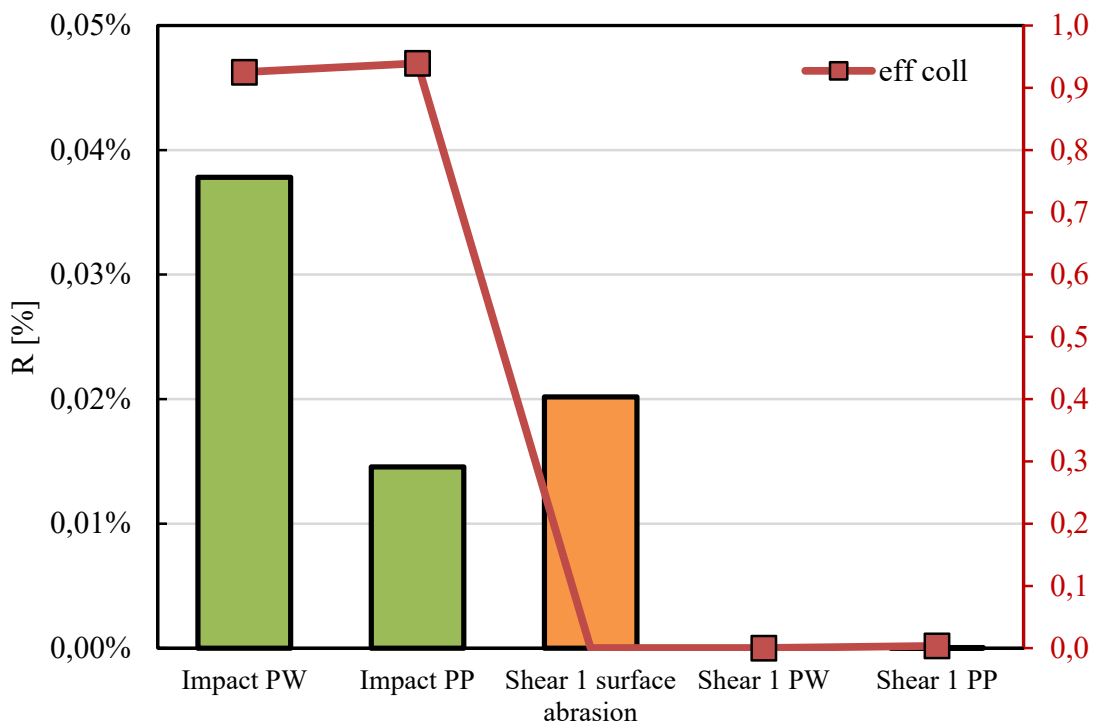

Figure 21. Extents of breakage, R, and collision efficiency factor, $\eta_{c}$, of the regions "Impact" (in green) and "Shear 1" (in orange) as a result of surface abrasion, particle-wall and particle-particle collisions 
Table 5. Frequency of collision $\dot{\mathrm{N}}_{\mathrm{c}}$, number of collisions per particle $\mathrm{N}_{\mathrm{c} / \mathrm{p}}$, angle of impact $\vartheta$, relative impact velocity $\Delta v_{p}$, collisional efficiency factor $\eta_{c}$, extent of breakage $R$ and rational contribution to the regional breakage $\mathrm{R} / \mathrm{R}_{\mathrm{i}}$, for regions "Impact" and "Shear 1".

\begin{tabular}{|l|c|c|c|c|c|}
\cline { 2 - 6 } & \multicolumn{2}{c|}{ Impact } & \multicolumn{2}{c|}{ Shear 1 } \\
\cline { 2 - 6 } & PW & PP & $\begin{array}{c}\text { Surface } \\
\text { Abrasion }\end{array}$ & PW & PP \\
\hline$\dot{\mathrm{N}}_{\mathrm{c}}\left[\mathrm{s}^{-1}\right]$ & 7387.81 & 1119.35 & - & 37034.40 & 3857.34 \\
\hline $\mathrm{N}_{\mathrm{c} / \mathrm{p}}[-]$ & 1.85 & 0.27 & - & 9.26 & 0.96 \\
\hline$\vartheta\left[{ }^{\circ}\right]$ & 27 & 34 & - & 26 & 13 \\
\hline$\Delta \mathrm{V}_{\mathrm{p}}\left[\mathrm{m} \mathrm{s}^{-1}\right]$ & 2.69 & 2.74 & - & 0.61 & 2.32 \\
\hline$\eta_{\mathrm{c}}[\%]$ & 92.5 & 93.4 & - & 0.00 & 0.36 \\
\hline $\mathrm{R}[\%]$ & 0.038 & 0.014 & 0.020 & 0.00 & 0.00 \\
\hline $\mathrm{R} / \mathrm{R}_{\mathrm{i}}[\%]$ & 72.21 & 27.79 & 99.73 & 0 & 0.27 \\
\hline
\end{tabular}

At first, it can be concluded that the region "Shear 1", where there is the transition from collisional attrition to surface abrasion by shear, attrition is caused by surface abrasion only, although there is still a number of particle-wall collisions per particle. Practically all the collisions in this region occur at velocities lower than the transition velocity. In general, all the collisions occurring from region "Shear 1" downwards are below this limit.

As discussed above the "Impact" region is the main source of attrition in the cyclone. In particular, particle-wall collisions are the main cause leading to $72 \%$ of attrition of the region and $42 \%$ of the overall cyclone attrition. The particle-wall and particle-particle impacts occur in both cases at very steep angles, respectively at $27^{\circ}$ for and $34^{\circ}$ with a relative impact velocity of about $2.7 \mathrm{~m} / \mathrm{s}$. The collision efficiency in both cases is high and nearly equal to 93\%. All the previous features being comparable, the number of collisions per particle is accountable for the difference in terms of attrition between the two cases. In fact, as reported in Table 5 a particle in the "Impact" region collides about 1.9 times with the wall but only 0.2 times with another particle. This occurrence is expected from a low solid loading case like 
ours.

More case studies at different solids loading and inlet velocity are required to elucidate the interplay between the attrition caused by particle-wall and particle-particle collisional and surface abrasion.

\section{Conclusions}

Particle attrition in a cyclone has been analysed by the CFD-DEM method using single particle breakage models of impact and shear. A conventional Stairmand cyclone design is used at low solids loading, where the particle-wall interactions causing attrition are dominant. When the particles enter the cyclone at a high velocity they experience an initial breakage upon impact on the cyclone walls. Subsequently they flow spirally downwards and experience abrasive wear due to sliding along the walls. The chipping model of Ghadiri \& Zhang is fitted to the breakage data of CLC particles, measured using two types of single particle impact tests. Archard's model of abrasive wear is used to simulate the abrasive wear caused by particle shear against the walls. The CFD-DEM simulation is performed using spheres of 755 $\mu \mathrm{m}$ diameter and the same density as CLC particles, with a solid loading of $0.31 \mathrm{~kg}_{\text {solid }} / \mathrm{kg}_{\text {air }}$ and an inlet air velocity of $40 \mathrm{~m} / \mathrm{s}$. The simulation quantified the relative contributions of the particle collisional and sliding behaviour in the cyclone. The breakage models are then coupled with the information obtained from the simulation in terms of particle dynamics. The overall attrition extent in the cyclone is then calculated and described as a function of the particle mechanical properties and process conditions. The major contributors to attrition are the entrance region and the initial sliding region, contributing around $81 \%$ of the total attrition where both collisions and sliding are dominant, as compared to further downstream regions. The overall cyclone attrition is therefore shared between particle-wall collisions, $42 \%$, particle-particle collisions $16 \%$ and surface abrasion by shearing $42 \%$. A methodology is 
therefore presented for identifying the relative importance of various regions in the cyclone in causing attrition and predicting the extent of attrition based on the mechanical properties of the particles and the dynamics of particle flow in cyclones.

\section{APPENDIX}

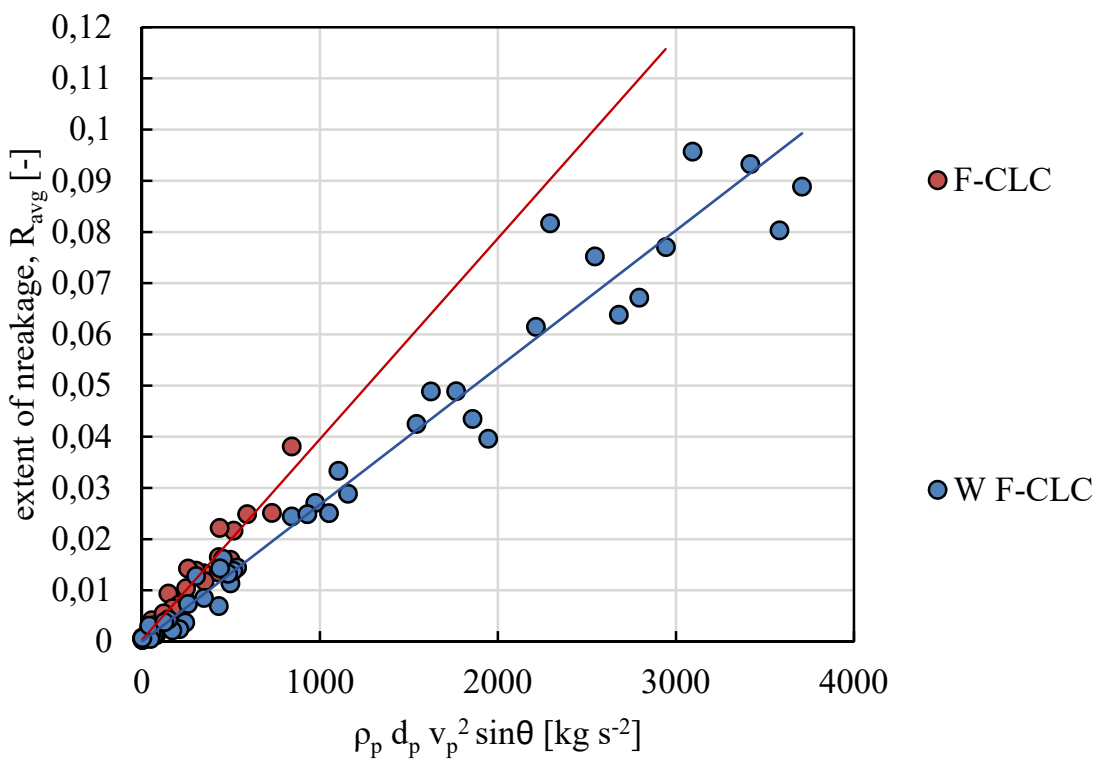

Figure A1. Comparison between non-washed (F-CLC) and washed material (W F-CLC) in terms of extent of breakage R plotted against $\rho_{\mathrm{p}} \mathrm{d}_{\mathrm{p}} \mathrm{v}_{\mathrm{p}}{ }^{2} \sin \theta$, obtained by SPIT

Table A1. Output of the simulations and calculated parameters

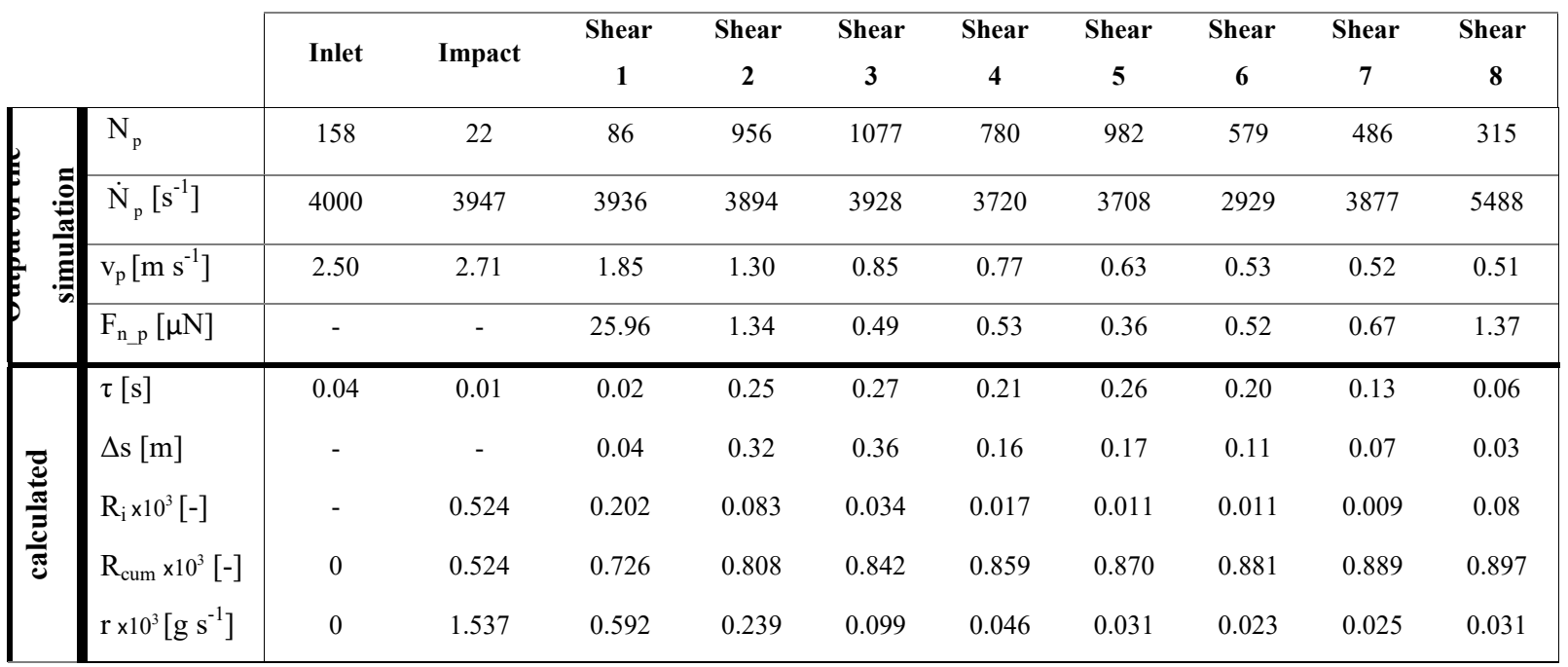

\section{REFERENCES}

[1] F. Zenz, G. Kelleher, Studies of attrition rates in fluid- particle systems via free fall, 
grid jets, and cyclone impact, in: Powder Bulk Technol., 4th ed., 1980: pp. 13-20.

[2] J. Welt, W. Lee, F.J. Krambeck, Catalyst attrition and deactivation in fluid catalytic cracking system, Chem. Eng. Sci. 32 (1977) 1211-1218.

[3] J. Werther, J. Reppenhagen, Catalyst Attrition in Fluidized-Bed Systems, AIChE J. 45 (2001) 2001-2010.

[4] J. Werther, J. Reppenhagen, Catalyst Attrition in Fluidized-Bed Systems, React. Kinet. Catal. 45 (1999) 2001-2010.

[5] J. Reppenhagen, J. Werther, Catalyst attrition in cyclones, Powder Technol. 113 (2000) 55-69.

[6] J. Werther, J. Reppenhagen, Attrition, in: W.C. Yang (Ed.), Handb. Fluid. FluidParticle Syst., CRC Press, 2003.

[7] K.W. Chu, B. Wang, D.L. Xu, Y.X. Chen, A.B. Yu, CFD-DEM simulation of the gassolid flow in a cyclone separator, Chem. Eng. Sci. 66 (2011) 834-847.

[8] M. Ghadiri, J.A.S. Cleaver, V.G. Tuponogov, J. Werther, Attrition of FCC powder in the jetting region of a fluidized bed, Powder Technol. 80 (1994) 175-178.

[9] J.F. Archard, J.F.A. Charj, Contact and Rubbing of Flat Surfaces, 24 (1953).

[10] Z. Zhang, M. Ghadiri, Impact attrition of particulate solids. Part 2: Experimental work, Chem. Eng. Sci. 57 (2002) 3671-3686.

[11] T. Bonakdar, M. Ali, S. Dogbe, M. Ghadiri, A. Tinke, A method for grindability testing using the Scirocco disperser, Int. J. Pharm. 501 (2016) 65-74.

[12] M. Ghadiri, Z. Zhang, Impact attrition of particulate solids. Part 1: A theoretical model of chipping, Chem. Eng. Sci. 57 (2002) 3659-3669.

[13] K.R. Yuregir, M. Ghadiri, R. Clift, Observations on impact attrition of granular solids, Powder Technol. 49 (1986) 53-57.

[14] C.C. Kwan, Y.Q. Chen, Y.L. Ding, D.G. Papadopoulos, A.C. Bentham, M. Ghadiri, Development of a novel approach towards predicting the milling behaviour of pharmaceutical powders, Eur. J. Pharm. Sci. 23 (2004) 327-336.

[15] M. Ali, T. Bonakdar, M. Ghadiri, A. Tinke, Particle Breakage in a Scirocco Disperser, Powder Technol. 285 (2015) 138-145.

[16] B.H. Xu, A.B. Yu, Numerical simulation of the gas-solid flow in a fluidized bed by combining discrete particle method with computational fluid dynamics, Chem. Eng. Sci. 52 (1997) 2785-2809.

[17] C.W. Haig, A. Hursthouse, S. Mcilwain, D. Sykes, An empirical investigation into the in fl uence of pressure drop on particle behaviour in small scale reverse-flow cyclones, Powder Technol. 275 (2015) 172-181.

[18] L.Y. Hu, L.X. Zhou, J. Zhang, M.X. Shi, Studies on strongly swirling flows in the full space of a volute cyclone separator, AIChE J. 51 (2005) 740-749.

[19] S. Yuu, T. Jotaki, T. Yuji, K. Yoshida, The reduction of pressure drop due to dust loading in a conventional cyclone, Chem. Eng. Sci. 33 (1978) 1573-1580. 
[20] J. Wei, H. Zhang, Y. Wang, Z. Wen, B. Yao, J. Dong, The gas-solid flow characteristics of cyclones, Powder Technol. 308 (2017) 178-192. 